\title{
The pitfalls of ignoring behaviour when quantifying habitat selection
}

\author{
C.L. Roever*1, H.L. Beyer*2, M.J. Chase ${ }^{1,3}$, and R.J. van Aarde ${ }^{1}$
}

1. Conservation Ecology Research Unit, Department of Zoology and Entomology, University of Pretoria, Hatfield, South Africa 0083.

2. ARC Centre of Excellence for Environmental Decisions, Centre for Biodiversity \& Conservation Science, University of Queensland, Brisbane, Queensland 4072, Australia

3. Elephants Without Borders, PO Box 682 Kasane, Botswana and Institute for Conservation Research, San Diego Zoo Global. E-mail: er@info.bw

* These authors contributed equally to this work.

Corresponding author: C. L. Roever. Conservation Ecology Research Unit, Department of Zoology and Entomology, University of Pretoria, Hatfield, South Africa 0083. Phone: +2712420 2753. Fax: +2712 420 4523. E-mail: mail@carrieroever.com

Running title: Behaviour and its consequences for habitat selection Article type: Biodiversity Research 


\section{Abstract}

Aim: Habitat selection is a behavioural mechanism by which animals attempt to maximize their inclusive fitness while balancing competing demands, such as finding food and rearing offspring while avoiding predation, in a spatially and temporally heterogeneous environment. Different habitat characteristics may be associated with each of these demands, implying that habitat selection varies depending on the behavioural motivations of the animal. Here, we investigate behaviour specific habitat selection in African elephants and discuss its implications for distribution modelling and conservation.

Location: Northern Botswana, Africa, case study.

Methods: We use Bayesian state-space models to characterize location time-series data of elephants into two behavioural states (encamped and exploratory). We then develop habitat selection models for each behavioural state and contrast them to models based on data pooled among behaviours.

Results: Spatial predictions of habitat use were often markedly different among the models. Behaviourspecific and pooled habitat selection models differed in model structure, the magnitude of model coefficients, and the form of the selection curve (linear or quadratic). Selection was typically strongest in the behaviour-specific models, though this varied according to behavioural state and habitat covariate.

Main conclusions: Ignoring behavioural states often had important consequences for quantifying habitat selection. Quantifying selection irrespective of behaviour (among all behaviours) can obscure important species-habitat relationships, thereby risking weak or incorrect inferences. Behaviour-specific habitat selection provides greater insight into the process of habitat selection and can improve predictive habitat selection estimates. As some behaviours are more relevant to specific conservation objectives than others, focusing on behaviour-specific selection could improve how habitats are prioritized for conservation or management.

\section{Key words}

African savannah elephant, behaviour, habitat selection, movement, resource selection function, statespace model 


\section{Introduction}

Animals must resolve a wide range of competing demands to survive and reproduce: find food, water and mates, avoid predators, defend a territory and care for offspring. These competing demands often mean that animals must prioritize actions or behaviours to meet one goal at the expense of another. Good foraging areas, for instance, may also be associated with higher mortality risk (Nielsen et al., 2006), or defending a territory may occur at the cost of acquiring food (Switalski, 2003). Although some behaviours can occur synchronously as a result of multitasking (Fortin et al., 2004), many behavioural strategies are employed asynchronously, often because the habitat characteristics associated with meeting different needs are spatially segregated. For instance, in an environment where food is patchily distributed, foraging within patches and moving between patches occur asynchronously (Owen-Smith et al., 2010).

Habitat selection modelling is used to quantify species-habitat relationships and may contribute to conservation and management (see Boyce \& McDonald, 1999; Chetkiewicz et al., 2006; Nielsen et al., 2006). However, as a consequence of competing demands, habitat selection may vary considerably depending on the behavioural priorities of the animal. Pooling data among behaviours can then result in three inferential pitfalls when quantifying habitat selection. First, if behaviours have opposing habitat selection patterns we may fail to detect selection. Consequently, a coefficient of zero in a habitat selection model that averages selection among all behaviours cannot be used as a basis for suggesting that there is no selection with respect to that covariate. Second, we may underestimate the strength of selection and, therefore, the importance of some habitats to an animal. For instance, strong but infrequent behaviour-specific selection for a critical habitat may be concealed by weak or no selection for that habitat at other times. Third, the direction or shape of the selection curve (how the probability of use changes as a function of a habitat covariate) is likely to be sensitive to behaviour. For instance, selection for a habitat characteristic may be positive during one behaviour, yet negative during another, or a selection curve may be approximately linear for one behaviour but better represented by a quadratic expression for another. Incorrect assessment of the importance, strength and form of selection ultimately reduces the inferential power of the resulting habitat selection models and has implications for the utility of these models when applied to conservation and management. Implicit in the application of a behaviour-pooled habitat selection model to make predictions of space use in new areas or to different times is the assumption that the ratio of behaviours from which the overall selection patterns arise will not change. 
Behaviour-specific habitat selection has received limited attention because habitat selection is often based on location data (e.g. telemetry data) that lacks a behavioural context (Beyer et al., 2010). Although the expression of behaviour is not recorded by satellite collars, behavioural state-space models (Morales et al., 2004) provide a framework by which behavioural "states" or "modes" can be estimated based on path characteristics (Beyer et al. 2013). These methods use the step length (or movement rate) and turn angle characteristics of the movement path to classify locations into different behavioural states based on a mixture of random walks (Morales et al., 2004). Here, we use this approach to test for behavioural differences in habitat selection using elephant telemetry data as a case study. In the dry season, African savannah elephants (Loxodonta africana) must fulfill competing physiological requirements. For instance, individuals must visit water regularly to meet several physiological needs (Wright \& Luck, 1984; Harris et al., 2008; Loarie et al., 2009). However, areas near water often are nutritionally depleted in the dry season (de Beer et al., 2006), so elephants travel away from water in search of forage. Elephants also reduce their mortality risk by avoiding human settlements (Roever, van Aarde, \& Chase, 2013a). We use a Bayesian state-space framework to classify telemetry locations into "encamped" and "exploratory" behavioural states and use resource selection functions to characterize habitat selection in each state. We find that the importance, strength and form of selection differ between behavioural states and among animals. We conclude that behaviourspecific selection provides greater insight into species-habitat relationships and offers opportunities for improving predictive estimates of spatial use that may be relevant for conservation and management.

\section{Methods}

\section{Study Area and elephant data}

The study area was located in northern Botswana and included Chobe National Park, Makgadikgadi National Park, Moremi Game Reserve and Nxai Pan National Park (Fig. 1). It encompassed an area of $74,355 \mathrm{~km}^{2}$ and was bounded to the north by Namibia and the east by Zimbabwe. Vegetation in the study area was primarily deciduous dry woodlands and interspersed grasslands (Chase, 2011), and terrain in the region was relatively flat, with the steepest slopes occurring along the Chobe River. Areas of high human use were mostly located around the periphery of the study area.

Within the study area, 11 elephants were collared with GPS collars (Africa Wildlife Tracking, Pretoria, South Africa) between August 2009 and September 2011. Collars were programmed to locate animals every hour, and only data from the 2011 dry season (July to November, inclusive) was used in 
this analysis. We had more than 1,000 locations per individual for this period, resulting in five females and six males with a total of 36,023 locations (see Table S1 in Supporting Information). For each individual, seasonal ranges were based on the $95 \%$ isopleths of a Gaussian kernel density estimate (Geospatial Modelling Environment; Beyer, 2011) using smoothed cross-validation (SCV) bandwidth estimators from the 'ks' library in R (Duong, 2012).

\section{Movement models}

Following Morales et al (2004) and McClintock et al (2012) we model movement as a combination of one or more discrete-time random walks (RWs), each characterized by distributions of movement rates $\left(r_{t}\right.$; the velocity between two consecutive spatial locations $X_{t}$ and $\left.X_{t+1}\right)$ and turn angles $\left(\phi_{t} ;\right.$ the angular difference in direction of travel between two consecutive steps, $X_{t-1}$ to $X_{t}$ and $X_{t}$ to $X_{t+1}$ ). When multiple RWs are used, each observation $y_{t}(t=1, \ldots, T)$ must be assigned to one of the RWs and parameters estimated for the probability distributions describing each RW. This can be formulated as a state-space model whereby a latent (unobserved) state indicator $Z_{t}=i, i \in\{1, \ldots, M\}$, where $\mathrm{M}$ is the number of movement states considered, is used to associate each observation with a RW (Morales et al 2004). For each RW, movement rates and turn angles are assumed to be independent and identically distributed, with movement rates drawn from a gamma distribution with rate parameter $a_{i}$ and shape parameter $b_{i}$, and turn angles drawn from a wrapped Cauchy distribution with parameters $\mu_{\mathrm{i}}$ and $\rho_{\mathrm{i}}(i \in\{1, \ldots, M\})$ representing the mean turn angle and dispersion parameters respectively. The movement process is thus a discrete-time, continuous-space, multi-state random walk with movement rate $\left[r_{t} \mid Z_{t}=\right.$ $i] \sim \operatorname{gamma}\left(a_{i}, b_{i}\right)$ and turn angle $\left[\phi_{t} \mid Z_{t}=i\right] \sim \mathrm{wCauchy}\left(\mu_{i}, \rho_{i}\right)$. Specifically, the probability density functions describing these distributions are:

$$
f\left(r_{t} \mid Z_{t}=i\right)=\frac{b_{i}^{a_{i}} r_{t}^{a_{i}-1} e^{-b_{i} r_{t}}}{\Gamma\left(a_{i}\right)}
$$

and

$$
f\left(\phi_{t} \mid Z_{t}=i\right)=\frac{1}{2 \pi} \frac{1-\rho_{i}^{2}}{1+\rho_{i}^{2}-2 \rho_{i} \cos \left(\phi_{t}-\mu_{i}\right)}
$$

where $a>0, b>0,0 \leq \mu \leq 2 \pi$, and $0 \leq \rho \leq 1$. Note that if $a=1$ the gamma distribution reduces to the exponential distribution. When $\rho=0$ the probability density is uniform over the circular range $0-2 \pi$, and becomes more peaked at $\mu$ as $\rho$ approaches 1 . 
Under the assumption that the movement rates and step lengths within each behavioural state are independent, the joint likelihood for $r_{t}$ and $\phi_{t}$, conditional on state vector $Z$ is:

$$
f(\boldsymbol{y} \mid \boldsymbol{Z})=\prod_{t=1}^{T} f\left(r_{t} \mid Z_{t}\right) f\left(\phi_{t} \mid Z_{t}\right)
$$

We evaluate three movement models. In the simplest ("single") movement model there is only one behavioural state $(M=1)$, no latent variables because $Z_{t}=1$ for all $t$. In the "double" and "switch" models we hypothesize there are two behavioural states $(M=2)$ including an "encamped" state $(i=1)$ and an "exploratory" state $(\mathrm{i}=2)$ that is characterized by faster movement rates and greater directional persistence than the encamped state. In the double model the probability of being in each state is assumed to be independent of previous states or environmental variables:

$$
Z_{t} \sim \operatorname{Categorical}\left(\eta_{1}, \eta_{2}\right)
$$

where $\eta_{i}$ is the fixed probability of being in state $i$ at any time $t$, and $\sum_{i=1}^{M} \eta_{i}=1$. In the switch model the current state, $Z_{\mathrm{t}}$, is related to the state of the animal in the previous time step, $Z_{\mathrm{t}-1}$. Specifically, switches between states are characterized by a first-order Markov process in discrete time (McClintock et al 2012):

$$
\left[Z_{t} \mid Z_{t-1}=k\right] \sim \operatorname{Categorical}\left(\psi_{k, 1}, \psi_{k, 2}\right)
$$

and

$$
\psi_{k, i}=\operatorname{Pr}\left(Z_{t}=i \mid Z_{t-1}=k\right)
$$

where $\psi_{\mathrm{k}, \mathrm{i}}$ is the probability of switching from state $k$ at time $t-1$ to state $i$ at time $t$, and $\sum_{i=1}^{M} \psi_{k, i}=1$. This is equivalent to the "double-switch" model in Morales et al. (2004).

The multistate models reflect the assumption that the exploratory state is characterized by movement rate and turn angle distributions with greater or equal mean movement rate and directional persistence, respectively, relative to the encamped state. Two constraints on priors were used to ensure that state index 2 always represented the exploratory state. Without these constraints the two states can be assigned different index values ( 1 or 2 ) among MCMC chains and these values can even switch within a single MCMC chain, complicating the interpretation of the posterior samples. The means of the encamped $\left(\bar{r}_{1}\right)$ and exploratory $\left(\bar{r}_{2}\right)$ gamma distributions were sampled using priors $\bar{r}_{1} \sim U(0,1.6)$ and $\bar{r}_{2} \sim U(0,1.6)+\bar{r}_{1}$, where $U(0,1.6)$ is a uniform distribution in the range 0-1.6 (1.6 was the maximum movement rate observed among all steps and animals). The two rate parameters of the gamma 
distributions $\left(a_{1}, a_{2}\right)$ were then sampled from vague priors $\left(a_{1} \sim \operatorname{gamma}(0.001,0.001)\right.$, $\left.a_{2} \sim \operatorname{gamma}(0.001,0.001)\right)$, and the shape parameters $\left(b_{1}, b_{2}\right)$ were calculated deterministically by dividing the rate parameter by the mean $\left(b_{1}=a_{1} / \bar{r}_{1}, b_{2}=a_{2} / \bar{r}_{2}\right)$. The priors for the dispersion parameters of the wrapped Cauchy distribution, $\rho_{1}$ and $\rho_{2}$, involved sampling two random variables from uniform distributions in the range $[0,1]$ and assigning the smaller of them to $\rho_{1}$. All other variables were sampled from vague priors. Specifically, $\eta$ and $\psi$ were sampled from uniform distributions in the range $[0,1]$, and $\mu$ was sampled from a uniform distribution over the range $[0-10 \pi]$ (the large range here helps to prevent boundary effects in the posteriors for $\mu$.

Models were fit using Monte Carlo Markov Chain (MCMC) techniques implemented in the software JAGS (Plummer, 2003) using three chains with a burn-in period of 10,000 samples, which were discarded, followed by 50,000 samples, thinned to retain every 25 th sample, resulting in 2,000 independent samples per chain from the posterior distribution of each parameter. Chains were initialized by sampling from the prior distributions (see Appendix S1 for full details). Every model was checked for convergence to a stationary distribution using the Gelman-Rubin convergence statistic $(R$; Gelman \& Rubin, 1992), whereby $R<1.1$ indicates convergence, and by visually examining plots of the chains and autocorrelation plots for each chain. $R$ was calculated using the "gelman.diag" function in the "coda" library in R (R Development Core Team, 2011). Model selection was informed by the widely applicable information criteria (WAIC; Watanabe, 2010).

\section{Resource selection models}

Using the top-ranked movement model for each individual, we partitioned the telemetry locations into encamped and exploratory behavioural states and quantified habitat selection for each behavioural state and for the pooled data (all telemetry locations irrespective of behavioural state). Resource selection for each individual was estimated by comparing the telemetry locations to random locations using the logistic form of the resource selection probability function (Manly et al., 2002; Lele \& Keim, 2006). Random locations were generated within the seasonal range of each individual at a density of 12 points per $\mathrm{km}^{2}$. The same set of random locations was used for the pooled, encamped and exploratory habitat selection models.

Selection was quantified for habitat covariates known to influence elephant habitat selection (Roever et al., 2012). Elephants are known to respond to water, slope, vegetative cover and human presence. The spatial location of water was mapped using community contributed GPS data from Tracks4Africa (Pretoria, South Africa) and was manually validated using Landsat imagery. In northern 
Botswana, water other than in rivers is scarce during the dry season; therefore, we used only water bodies classified as main rivers, river deltas, dams and man-made watering holes for this dry season analysis. Distance to water was calculated for all landscape locations. Slope was calculated from a $90 \mathrm{~m}$ digital elevation model (Jarvis et al., 2006), and percent tree cover at a 500m resolution was obtained from Moderate Resolution Imaging Spectrometer (MODIS) Vegetation Continuous Fields product (Hansen et al., 2006). The $500 \mathrm{~m}$ tree cover layer was resampled to a $90 \mathrm{~m}$ resolution using a cubic convolution interpolation to match the resolution of the other datasets. Finally, human density data at a $1 \mathrm{~km}$ resolution was obtained from Landscan (2008) daily human population data. Hoare and Du Toit (1999) found that elephants avoid areas with greater than 16 people/ $\mathrm{km}^{2}$, so we identified all areas with human densities greater than this value and calculated distance to these high human use areas. All geospatial analysis was completed using the Spatial Analyst extension of ArcGIS 10.0 (ESRI, Redlands, California) and Geospatial Modelling Environment (Beyer, 2011).

Using the suite of habitat covariates described, five candidate models were formulated (Table 1), and Bayesian information criterion (BIC; Schwarz 1978) was used to identify the top-ranked habitat selection model for the two behavioural state datasets and the pooled dataset of each individual. Covariates with Pearson's $r>0.6$ were not included in the same model. For six individuals, distance to water was correlated with distance to humans, so only candidate models 1 and 2 were evaluated. To assess the fit of the top-ranked model for each individual, we used $k$-fold cross validation $(k=5)$, whereby, for each individual, a model is iteratively (k times) fit to $80 \%(1-N / k)$ of the data and validated using the remaining $20 \%(\mathrm{~N} / \mathrm{k})$ of the data. Fit is quantified using the Spearman rank correlation coefficient based on the frequency of used points in each of 10 equal area bins of predicted values (see Boyce et al., 2002). For the pooled model the full dataset was used for fitting and validation, while only the data corresponding to each behavioural state was used to fit and validate the behaviourspecific models. Selection probabilities for habitat covariates were calculated using:

$$
w(x)=e^{X \beta} /\left(1+e^{X \beta}\right),
$$

where $w(x)$ is the resource selection probability function, $X$ is a matrix of habitat covariates (including a column of ones representing the intercept term) and $\beta$ is the vector of maximum likelihood estimates of the model coefficients. To assess overall predictive power, we compared the model fit of the pooled model against a behaviourally averaged model, $b(x)=\sum_{i=1}^{I} p_{i} w\left(x_{i}\right)$, for each individual where $p_{\mathrm{i}}$ is the proportion of locations in the $i$ th behavioural state and $w\left(x_{i}\right)$ is the resource selection model for that 
state. We quantified model fit of both the pooled and averaged model using the Spearman rank correlation coefficient as described above.

Finally, to test whether selection for habitat covariates differed significantly between the encamped and exploratory states, we contrasted exploratory (0) and encamped (1) data for each individual using latent selection difference (LSD) functions (Czetwertynski, 2007; Latham et al., 2011). Because availability remains constant across behavioural states for each individual, this model provides direct comparisons of selection with significance and strength measures (Czetwertynski, 2007). For each individual, the same model structure was used as in the top-ranked model from the use versus available analysis; however, if model structure between the encamped and exploratory state differed, we used the more complete model. To reduce the probability of a Type I error resulting from serially correlated telemetry data, we used Newey-West variance inflation when estimating standard errors (Newey \& West, 1987, Nielsen et al. 2002). Using auto-correlation functions (ACF), we found evidence of temporal autocorrelation in the step lengths of individuals every 12 hours in the pooled elephant data. This pattern was corroborated with the classified behavioural data, as the mean time an individual spent in the same state ranged from 3 to 12 hours among individual. To be conservative, we used a lag of 12 for all individuals and models. All analysis were conducted in R ( $R$ Development Core Team, 2011) using the "ResourceSelection" library (Lele et al., 2011).

\section{Results}

The switch model, in which the probability of switching between states was explicitly estimated, was the top-ranked movement model for most (9 of 11) individuals (see Table S2-3). However, for males EM0190 and EM0198 the double model, which indicated that switching probabilities among states could be reasonably approximated as constants, was the top-ranked model. Although the switch model was the highest-ranked model using WAIC for animal EM0195, it was characterized by long periods ( $>18$ days) of no state switching. This is not consistent with our knowledge of elephant behaviour and was not supported by the double model, so for this animal we used the double model. In all cases, the behavioural state models far out-ranked the reference model (the single behavioural state model). Locations classified as exploratory had longer step lengths and greater directional persistence than points classified as encamped, which were generally clumped with shorter step lengths and larger turn angles (Fig. 2). 
The model structure of the pooled and behaviour-specific habitat selection models sometimes differed. While 7 of 11 individuals had top-ranked model structure that did not vary among behavioural states (pooled, encamped, exploratory), for four elephants the encamped or exploratory model structure differed from that of the other two models (Table 2). When model structure varied between behavioural states, the pooled model structure did not consistently resemble one movement state preferentially. Instead, the pooled model structure was generally the same as the behavioural state with the most complex structure (i.e. with the most covariates).

The top-ranked habitat selection models provided good fit to the data using $\mathrm{k}$-fold cross validation tested with the Spearman rank correlation coefficient $\left(r_{s} \geq 0.68, p<0.05\right)$ for all elephants (Table 2). For EM0192 the pooled model fit was relatively low $\left(r_{s}=0.68, p<0.05\right)$, but the encamped $\left(r_{s}\right.$ $=0.84, p<0.01)$ and exploratory $\left(r_{s}=0.92, p<0.01\right)$ model fit was better. Averaging the behaviourspecific models for EM0192 into a behaviourally averaged model then provided moderately better fit $\left(r_{s}\right.$ $=0.96, p<0.01)$ than the pooled model, which did not incorporate behaviour; however fit of both models were significantly positive. For all other elephants, the behaviour-averaged model and the pooled model performed equally well (see Fig. S1).

Coefficient values often differed markedly between the state-specific and pooled models (Fig. 3, see Fig S2 for confidence intervals). With respect to selection for slope, for example, among all animals we found that the encamped and exploratory states were associated with a $15 \%$ increase ( $\pm 36 \%$ s.d.) and a $35 \%$ decrease $( \pm 51 \%$ s.d.) in the magnitude of the coefficient relative to the pooled selection model, respectively, although the response of individuals varied (e.g. Fig. 3). For EM0181, distance to human development was a statistically significant predictor of habitat selection in the encamped and pooled model, but this variable was not included in the top ranked model for the exploratory datasets. We also found that behaviour influenced whether the $95 \%$ confidence intervals of the coefficient crossed zero (hereafter "significance"). For individual EF0199, for example, selection for water was significant in the encamped and exploratory models, yet in the pooled model, selection for water was not significant (see Table S4).

In addition to strength and significance, we also found the form of the selection curve changed. For the two females and two males displayed in Fig. 3, for example, there were marked differences in selection between the exploratory, encamped and pooled models with respect to distance to water and proportion of tree cover (also see Fig. S2). For EF0194, the relationship was linear in the exploratory state, yet quadratic in the pooled and encamped states for these two covariates. We also expected to 
find differences with respect to the sign (e.g. positive or negative) of the selection coefficient; however, for the elephants examined here, we found very few sign changes. All of the differences we did observe were associated with quadratic covariates, resulting in changes to the form of the quadratic function. . While selection for steeper slopes was consistent across the four animals in the example, the strength (i.e. slope) of the selection coefficients varied.

The differences in habitat selection coefficients identified between the encamped and exploratory states were significant in many cases (Table 3). For most individuals (9 of 11), we found significant differences in selection for at least one habitat covariate between the encamped and exploratory behavioural states. For six of these individuals, selection varied significantly for two or more habitat covariates. These differences in the habitat selection coefficients resulted in markedly different habitat use patterns (e.g. EF0197; Fig. 4). Despite the differences in habitat selection observed here, consistencies in habitat selection also often occurred among the behaviour specific models. For example, EF0191 and EF0196 had no significant differences in selection between the encamped and exploratory states for any habitat covariate examined here.

\section{Discussion}

We demonstrate that behaviour-specific habitat selection provides greater insight into species-habitat relationships compared to models that pool data among behaviours. In particular, we found evidence of all three inferential pitfalls in our case study. First, opposing selection for a habitat covariate among behavioural states "cancelled out" in a pooled model, resulting in the conclusion that selection was either weak or non-existent with respect to this covariate. With female EF0199, for example, selection for water was significant in both behaviour-specific models, yet was not significant in the top ranked pooled model. Second, the strength of selection was substantially underestimated for some habitat covariates when pooling data from different behavioural states. Selection by elephants for slope was on average $15 \%$ larger in the encamped model and 35\% smaller in the exploratory model compared to the pooled model. Finally, the form of the selection curve (how relative probability of use changes as a function of a habitat covariate) was sensitive to behavioural state. For five animals, the shape of the response changed from a straight line to a quadratic function (Fig. 3). Thus, if habitat selection is multimodal, driven by behaviour-specific habitat associations and movement characteristics, then the mean selection pooled among all behaviours may provide poor insight into selection. Furthermore, incorrect assessment of the importance of habitat covariates, or the strength or form of selection, is 
problematic for the extrapolation of selection models to estimate selection in other areas or at other times. Although only observed for a subset of individuals and covariates, this work highlights the existence and importance of these inferential pitfalls.

An important implication of our work is that if habitat selection is behaviour-specific then we must understand both how selection varies among behavioural states and the factors determining the proportion of time spent in different behavioural states. Implicit in the use of pooled selection models for predictive purposes, for instance, is the assumption that the ratio of behaviours from which the overall selection patterns arise will not change. Here, elephants spent approximately equal proportion of time in the encamped and exploratory behavioural states (47.9\% and $52.1 \%$, respectively, s.d. $18.8 \%$ ). This likely contributed to the similar model fit of the pooled and behaviourally averaged habitat selection models (see Fig. S1). However, no studies have examined how elephant behaviour changes as a function of resource availability. The proportions of time spent in different behaviours may vary temporally as climatic conditions alter the availability of water, vegetation and shade cover. High behavioural plasticity would further reduce the robustness of habitat selection models to other locations and times. While only two behaviours were assessed here, additional subdivision of elephant behaviour may further elicit insightful elephant-habitat associations.

Another important implication of this work is that quantifying behaviour-specific selection reduces the risk of failing to identify important habitat selection patterns. Though model structure did not vary between behaviours for most elephants examined here, the significance and strength of selection coefficients did, and in one instance a significant covariate in the encamped and exploratory models was not significant in the top model for the pooled dataset (i.e. EF0199 and selection for water). Pooling location data may obscure selection for habitats that occur uncommonly or briefly, but still have important effects on survival or fitness. In the African savannah, for example, accessing watering holes is essential for many species, but watering holes are also dangerous places because predators often concentrate around them (de Boer et al., 2010). Thus under conditions where the animal is not experiencing water or thermal stress, animals may spend much of their time away from watering holes and visit them only briefly, despite their importance for survival.

Incorporating behaviour into habitat selection estimates provides a more mechanistic perspective on species-habitat relationships and offers opportunities for the development conservation and management initiatives. If some behaviours contribute more to the fitness of individuals than others, the habitat associated with these particular behaviours may provide opportunities for improving 
management or conservation efficiency and effectiveness. Corridors, for example, are often designed using the habitat preferences of one or more species (Chetkiewicz et al., 2006). Designing corridors based on the habitat selection (i.e. Roever et al. 2013b) during the exploratory behavioural state, for example, may better facilitate corridor use and animal movement in heterogeneous landscapes. Incorporating behaviour into habitat selection studies allows us to identify those behaviours most important for fitness or conservation and tailor management action towards the facilitation of those goals. Conversely, some habitat characteristics may be important for animal selection irrespective of behaviour, and these similarities in selection also add to our understanding of the biology of species.

The disconnect between studies of animal behaviour and habitat selection often results as a consequence of those two disciplines operating at different spatiotemporal scales (Lima \& Zollner, 1996). Animal behaviour studies generally examine fine scale selection of microhabitats or food items, whereas habitat selection studies typically assess species-habitat relationships at broader scales. The challenge has been how to integrate these two (Lima \& Zollner, 1996). Distinguishing behaviour-specific selection can provide new insights into species-habitat relationships. In our case study, the strength of selection for one of the female elephants (EF0197) was strongest in the encamped state and the spatial distribution of selected habitats were patchy (Fig. 4(c)) compared to the more uniform distribution of selected habitat for the exploratory state (Fig. 4(d)). Averaging these two behaviour specific models then resulted in a noticeable different resource selection function (Fig. 4(b)) than that of the pooled model (Fig. 4(a)), although both provided good fit to the data.

Ultimately, models that combine both movement modelling and habitat selection in a single framework are likely to offer the greatest inferential power because these two processes are not independent (Beyer et al., 2010; Fieberg et al., 2010). For instance, habitat effects can be incorporated into state-space movement models (Morales et al., 2004; Jonsen et al., 2005; Forester et al., 2007; Eckert et al., 2008) and into diffusion models (Moorcroft et al., 2006; Johnson et al., 2008). These methods are, however, often computationally intensive or analytically intractable and impractical to apply to large telemetry datasets. In lieu of these more comprehensive approaches, we used statespace models to estimate behavioural states based only on the characteristics of the movement paths (but not habitat covariates), and we subsequently quantified habitat selection using generalized linear models for each animal. Although not an ideal solution, it does demonstrate the premise of this work: that resource selection is behaviour-specific. 
Using more mechanistic models of species-habitat relationships at the level of the individual may also improve our ability to predict distribution at the population level, though scaling up from individuals to populations is not straightforward. Selection varies as a function of the samples of use and availability, making it difficult to directly compare selection quantified over different availabilities (Beyer et al., 2010). Although one common approach to making population-level inferences is to estimate population-averaged selection (e.g. the marginal inferences from a generalized linear mixed model where individual is treated as a random effect), it might be better to quantify selection in terms of functional responses (Mysterud and Ims, 1998), whereby selection is modelled as a function of the availabilities of all habitats (Matthiopoulos et al., 2011). By explicitly quantifying how selection changes as availability changes, predictions from functional response models are likely to be more robust when applied to new regions (where animals were not sampled). Using a functional response model to make spatial predictions of population distribution requires an understanding of how social interactions affect availability (i.e. determining an appropriate scale over which to assess availability in order to apply the functional response model), which is an area of active research.

In conservation, the aim of habitat selection studies is often to predict changes in habitat use based on some future scenario, alternative management strategy, or predict species distribution in a new region. Yet if we fail to understand the processes driving selection, our projections and any subsequent inferences could be weak or incorrect. By incorporating behavioural processes into habitat selection we might move a step beyond describing patterns to better understanding the behavioural mechanisms that drive selection processes (Beyer et al., 2010). As habitat selection studies are applied increasingly to conservation issues such as reserve and corridor design (e.g. Cabeza et al., 2004; Chetkiewicz \& Boyce, 2009; Roever et al., 2013b), it is imperative that estimates are robust and that habitat is appropriately characterized in ways that are most relevant to the survival and, ultimately, fitness of wildlife species.

\section{Acknowledgements}

We would like to thank the International Fund for Animal Welfare (IFAW), the University of Pretoria, the Australian Research Council (ARC) Centre of Excellence for Environmental Decisions (CEED) and the Environmental Decisions Group at the University of Queensland for research funding and support. GIS data was provided by Tracks4Africa and the research was sanctioned and supported by the Botswana Department of Wildlife \& National Parks. Elephants Without Borders was funded by the Paul G. Allen 
Family Foundation, Jody Allen, Zoological Society of San Diego, Madeleine and Jerry Delman Cohen, Harry Ferguson, Botswana Government Conservation Trust Fund, and Wilderness Trust. We acknowledge the support of Cyril Taolo, Larry Patterson, Peter Perlstein, Mike Holding and Abu Camp. We thank Hugh Possingham for his comments, and we are grateful to Juan M. Morales for his insightful comments on our Bayesian analysis.

\section{References}

Beyer, H.L. (2011) Geospatial Modelling Environment. Spatial Ecology, LLC. Available at: http://www.spatialecology.com/gme/ (accessed April 2012).

Beyer, H.L., Haydon, D.T., Morales, J.M., Frair, J.L., Hebblewhite, M., Mitchell, M. \& Matthiopoulos, J. (2010) The interpretation of habitat preference metrics under use-availability designs. Philosophical Transactions of the Royal Society B-Biological Sciences, 365, 2245-2254.

Beyer, H.L., Morales, J.M., Murray, D.L., \& Fortin, M.-J. (2013) Estimating behavioural states from movement paths using Bayesian state-space models: a proof of concept. Methods in Ecology and Evolution, 4(5), 433-441.

Boyce, M.S. \& McDonald, L.L. (1999) Relating populations to habitats using resource selection functions. Trends in Ecology \& Evolution, 14, 268-272.

Boyce, M.S., Vernier, P.R., Nielsen, S.E. \& Schmiegelow, F.K.A. (2002) Evaluating resource selection functions. Ecological Modelling, 157, 281-300.

Cabeza, M., Araujo, M.B., Wilson, R.J., Thomas, C.D., Cowley, M.J.R. \& Moilanen, A. (2004) Combining probabilities of occurrence with spatial reserve design. Journal of Applied Ecology, 41, 252-262.

Chase, M. (2011) Dry season fixed-wing aerial survey of elephants and wildlife in northern Botswana, September - Novermber 2010. Tech. Rep. Elephants Without Borders, Kasane.

Chetkiewicz, C.-L.B., Clair, C.C.S. \& Boyce, M.S. (2006) Corridors for conservation: Integrating pattern and process. Annual Review of Ecology Evolution and Systematics, 37, 317-342. 
Chetkiewicz, C.L.B. \& Boyce, M.S. (2009) Use of resource selection functions to identify conservation corridors. Journal of Applied Ecology, 46, 1036-1047.

Czetwertynski, S.M. (2007) Effects of hunting on the demographics, movement, and habitat selection of American black bears (Ursus americanus). University of Alberta, Edmonton.

de Beer, Y., Kilian, W., Versfeld, W. \& van Aarde, R.J. (2006) Elephants and low rainfall alter woody vegetation in Etosha National Park, Namibia. Journal of Arid Environments, 64, 412-421.

de Boer, W.F., Vis, M.J.P., de Knegt, H.J., Rowles, C., Kohi, E.M., van Langevelde, F., Peel, M., Pretorius, Y., Skidmore, A.K., Slotow, R., van Wieren, S.E. \& Prins, H.H.T. (2010) Spatial distribution of lion kills determined by the water dependency of prey species. Journal of Mammalogy, 91, 12801286.

Duong, T. (2012) ks: Kernel smoothing. R package version 1.8.7. Available at: http://CRAN.Rproject.org/package=ks (accessed April 2012).

Eckert, S.A., Moore, J.E., Dunn, D.C., van Buiten, R.S., Eckert, K.L. \& Halpin, P.N. (2008) Modeling loggerhead turtle movement in the Mediterranean: Importance of body size and oceanography. Ecological Applications, 18, 290-308.

Fieberg, J., Matthiopoulos, J., Hebblewhite, M., Boyce, M.S. \& Frair, J.L. (2010) Correlation and studies of habitat selection: problem, red herring or opportunity? Philosophical Transactions of the Royal Society B-Biological Sciences, 365, 2233-2244.

Forester, J.D., Ives, A.R., Turner, M.G., Anderson, D.P., Fortin, D., Beyer, H.L., Smith, D.W. \& Boyce, M.S. (2007) State-space models link elk movement patterns to landscape characteristics in Yellowstone National Park. Ecological Monographs, 77, 285-299.

Fortin, D., Boyce, M.S., Merrill, E.H. \& Fryxell, J.M. (2004) Foraging costs of vigilance in large mammalian herbivores. Oikos, 107, 172-180. 
Gelman, A. \& Rubin, D. (1992) Inference from iterative simulation using multiple sequences. Statistical Science, 7, 457-472.

Hansen, M., DeFries, R.S., Townshend, J.R., Carroll, M., Dimiceli, C. \& Sohlberg, R. (2006) Vegetation Continuous Fields MOD44B, 2001 Percent Tree Cover, Collection 4. University of Maryland, College Park, Maryland, 2001.

Harris, G.M., Russell, G.J., van Aarde, R.I. \& Pimm, S.L. (2008) Rules of habitat use by elephants Loxodonta africana in southern Africa: insights for regional management. Oryx, 42, 66-75.

Hoare, R.E. \& du Toit, J.T. (1999) Coexistence between people and elephants in African savannas. Conservation Biology, 13, 633-639.

Jarvis, A., Reuter, H.I., Nelson, A. \& Guevara, E. (2006) Hole-filled seamless SRTM data V3. International Centre for Tropical Agriculture (CIAT). Available at: http://srtm.csi.cgiar.org (accessed September 2010).

Johnson, D.S., Thomas, D.L., Ver Hoef, J.M. \& Christ, A. (2008) A General Framework for the Analysis of Animal Resource Selection from Telemetry Data. Biometrics, 64, 968-976.

Jonsen, I.D., Flenming, J.M. \& Myers, R.A. (2005) Robust state-space modeling of animal movement data. Ecology, 86, 2874-2880.

LandScan (2008) High Resolution global Population Data Set. Copyrighted by UT-Battelle, LLC, operator of Oak Ridge National Laboratory under Contract No. DE-AC05-00OR22725 with the United States Department of Energy.

Latham, A.D.M., Latham, M.C. \& Boyce, M.S. (2011) Habitat selection and spatial relationships of black bears (Ursus americanus) with woodland caribou (Rangifer tarandus caribou) in northeastern Alberta. Canadian Journal of Zoology, 89, 267-277.

Lele, S.R. \& Keim, J.L. (2006) Weighted distributions and estimation of resource selection probability functions. Ecology, 87, 3021-3028. 
Lele, S.R., Keim, J.L. \& Solymos, P. (2011) Resource selection (probability) functions for use-available data. $\mathrm{R}$ package version 0.1-4. Available at: http://CRAN.Rproject.org/package=ResourceSelection (accessed July 2012).

Lima, S.L. \& Zollner, P.A. (1996) Towards a behavioral ecology of ecological landscapes. Trends in Ecology \& Evolution, 11, 131-135.

Loarie, S.R., Van Aarde, R.J. \& Pimm, S.L. (2009) Fences and artificial water affect African savannah elephant movement patterns. Biological Conservation, 142, 3086-3098.

Manly, B.F.J., McDonald, L.L., Thomas, D.L., McDonald, T.L. \& Erickson, W.P. (2002) Resource Selection by Animals: Statistical Design and Analysis for Field Studies, 2 edn. Kluwer Academic Publishers, Dordrecht.

Mathiopoulos, J., Hebblewhite, M., Aarts, G. \& Fieberg, J. (2011) Generalized functional responses for species distributions. Ecology, 92(3), 583-589.

Moorcroft, P.R., Lewis, M.A. \& Crabtree, R.L. (2006) Mechanistic home range models capture spatial patterns and dynamics of coyote territories in Yellowstone. Proceedings of the Royal Society BBiological Sciences, 273, 1651-1659.

Morales, J.M., Haydon, D.T., Frair, J., Holsiner, K.E. \& Fryxell, J.M. (2004) Extracting more out of relocation data: Building movement models as mixtures of random walks. Ecology, 85, 24362445.

Mysterud A. \& Ims R.A. (1998) Functional responses in habitat use: availability influences relative use in trade-off situations. Ecology, 79, 1435-1441.

Nielsen, S.E., Stenhouse, G.B. \& Boyce, M.S. (2006) A habitat-based framework for grizzly bear conservation in Alberta. Biological Conservation, 130, 217-229. 
Owen-Smith, N., Fryxell, J.M. \& Merrill, E.H. (2010) Foraging theory upscaled: the behavioural ecology of herbivore movement. Philosophical Transactions of the Royal Society B-Biological Sciences, 365, 2267-2278.

Plummer, M. (2003) JAGS: A Program for Analysis of Bayesian Graphical Models Using Gibbs Sampling, Proceedings of the 3rd International Workshop on Distributed Statistical Computing (DSC 2003), March 20-22, Vienna, Austria. ISSN 1609-395X.

R Development Core Team (2011) R: A language and environment for statistical computing. $\mathrm{R}$ Foundation for Statistical Computing, Vienna, Austria. ISBN 3-900051-07-0. Available at: http://www.R-project.org (accessed April 2012).

Roever, C.L., van Aarde, R.J. \& Leggett, K. (2013a) Incorporating mortality into habitat selection to identify secure and risky habitats for savannah elephants. Biological Conservation, 164, 98-106.

Roever, C.L., van Aarde, R.J. \& Leggett, K. (2013b) Functional connectivity with conservation networks: Delineating corridors for African elephants. Biological Conservation, 157, 128-135.

Roever, C.L., van Aarde, R.J. \& Leggett, K. (2012) Functional responses in the habitat selection of a generalist mega-herbivore, the African savannah elephant. Ecography, 35, 972-982.

Schwarz ,G. (1978) Estimating the dimension of a model. Annual Statistics, 6, 461-464.

Switalski, T.A. (2003) Coyote foraging ecology and vigilance in response to gray wolf reintroduction in Yellowstone National Park. Canadian Journal of Zoology-Revue Canadienne De Zoologie, 81, 985993.

Wright, P.G. \& Luck, C.P. (1984) Do elephants need to sweat. South African Journal of Zoology, 19, 270274. 
Table 1. Competing habitat selection models relating habitat use to distance to water ("water"), percent tree cover ("tree"), slope, and distance to human settlement ("human"). The number of parameters (K) includes an intercept term. Models were fit to behavioural state-specific and pooled datasets and ranked using BIC.

\begin{tabular}{lll}
\hline Name & Candidate Model & $\mathrm{K}$ \\
\hline 1. Landscape & water + tree + slope & 4 \\
2. Landscape (non-linear) & water $+(\text { water })^{2}+$ tree $+(\text { tree })^{2}+$ slope & 6 \\
3. No Slope & water $+(\text { water })^{2}+$ tree $+(\text { tree })^{2}+$ human $+(\text { human })^{2}$ & 7 \\
4. Full (humans linear) & water $+(\text { water })^{2}+$ tree $+(\text { tree })^{2}+$ slope + human & 7 \\
5. Full & ${\text { water }+(\text { water })^{2}+\text { tree }+(\text { tree })^{2}+\text { slope }+ \text { human }+(\text { human })^{2}}$ & 8 \\
\hline
\end{tabular}


Table 2. The top-ranked pooled and behavioural-state specific habitat selection model, model weight $(w)$, and Spearman rank correlation coefficient $\left(r_{s}\right)$ derived from the k-fold cross validation, for each animal. Models were fit separately to each individual. See Table 1 for a description of models.

\begin{tabular}{|c|c|c|c|c|c|c|c|c|c|}
\hline \multirow[b]{2}{*}{ Elephant } & \multicolumn{3}{|c|}{ Pooled } & \multicolumn{3}{|c|}{ Encamped } & \multicolumn{3}{|c|}{ Exploratory } \\
\hline & Model & w & $r_{s}$ & Model & w & $r_{\mathrm{s}}$ & Model & w & $r_{s}$ \\
\hline EF0191 & 3 & 0.94 & 0.94 & 3 & 0.99 & 0.92 & 3 & 1.00 & 0.89 \\
\hline EF0194 ${ }^{1}$ & 2 & 1.00 & 1.00 & 2 & 1.00 & 0.99 & 1 & 0.99 & 0.87 \\
\hline EF0196 & 5 & 1.00 & 0.99 & 5 & 1.00 & 0.99 & 5 & 1.00 & 1.00 \\
\hline $\mathrm{EF} 0197^{1}$ & 2 & 1.00 & 0.99 & 1 & 0.97 & 0.99 & 2 & 1.00 & 0.98 \\
\hline EF0199 ${ }^{1}$ & 1 & 0.90 & 0.76 & 2 & 0.67 & 0.92 & 1 & 1.00 & 0.75 \\
\hline EM0181 & 5 & 1.00 & 0.85 & 5 & 0.96 & 0.95 & 1 & 0.72 & 0.87 \\
\hline EM0187 ${ }^{1}$ & 2 & 1.00 & 0.93 & 2 & 1.00 & 0.81 & 2 & 1.00 & 0.98 \\
\hline $\mathrm{EMO}^{190^{1}}$ & 2 & 1.00 & 0.98 & 2 & 0.52 & 0.98 & 2 & 1.00 & 0.99 \\
\hline EM0192 & 3 & 1.00 & 0.68 & 3 & 1.00 & 0.84 & 3 & 0.92 & 0.92 \\
\hline $\mathrm{EM} 195^{1}$ & 2 & 1.00 & 0.92 & 2 & 1.00 & 0.94 & 2 & 1.00 & 0.93 \\
\hline EM0198 & 5 & 1.00 & 0.94 & 5 & 1.00 & 0.95 & 5 & 1.00 & 0.99 \\
\hline
\end{tabular}

${ }^{1}$ Correlations occurred between water and humans, so only models 1-2 were considered for model selection. 
Table 3. The difference in selection between the exploratory (0) and encamped (1) behavioural states as quantified by latent selection difference functions for each elephant using Newey-West variance inflation. All but two individuals had significant $(*)$ differences in selection for at least one habitat covariate.

\begin{tabular}{|c|c|c|c|c|c|c|}
\hline & EF0191 & EF0194 & EF0196 & EF0197 & EF0199 & \\
\hline watert & 16.03 & 5.70 & -2.19 & $-25.06 *$ & $-7.37 *$ & \\
\hline$(\text { water })^{2}+\dagger$ & -30.56 & $-3.67 *$ & 0.89 & $13.23 *$ & & \\
\hline tree & 7.19 & $17.79 *$ & 3.62 & $-8.62 *$ & $1.88 *$ & \\
\hline$(\text { tree })^{2}$ & -29.17 & $-53.68 *$ & 0.44 & $23.67 *$ & & \\
\hline slope & & -0.12 & 0.03 & 0.18 & 0.10 & \\
\hline human & 0.35 & & 0.07 & & & \\
\hline \multirow[t]{2}{*}{ (human) $)^{2} \dagger$} & -0.46 & & -0.19 & & & \\
\hline & EM0181 & EM0187 & EM0190 & EM0192 & EM0195 & EM0198 \\
\hline water $\dagger$ & 7.05 & $-28.59 *$ & 0.38 & 0.96 & $22.16 *$ & $69.57 *$ \\
\hline$(\text { water })^{2}+\dagger$ & 2.20 & $10.17 *$ & 0.03 & 0.03 & $-3.18 *$ & $-50.70 *$ \\
\hline tree & $13.99 *$ & -1.52 & -0.36 & $13.86 *$ & 5.52 & 6.31 \\
\hline$(\text { tree })^{2}$ & $-62.32 *$ & 1.41 & -7.13 & -30.89 & $-38.38 *$ & -8.75 \\
\hline slope & 0.10 & -0.16 & $0.42 *$ & & 0.08 & $0.35 *$ \\
\hline human & -0.13 & & & $0.46^{*}$ & & $1.58 *$ \\
\hline (human) $)^{2} \dagger$ & 0.87 & & & $-0.46 *$ & & $-1.53 *$ \\
\hline
\end{tabular}

$\uparrow$ Coefficients multiplied by $100 ; \uparrow \uparrow$ Coefficients multiplied by 1000 


\section{List of Figures}

Figure 1. Study area located in northern Botswana (Albers Equal Area Conic projection). The study area included 3 national parks and 1 game reserve (dark grey), along with multiple wildlife management areas (light grey).

Figure 2. Elephant telemetry locations classified into encamped and exploratory behavioural states for one representative individual elephant (EM0181). Turn angle (circular plots in radians) and movement rate $(\mathrm{m} / \mathrm{s})$ differed between the two states, with the exploratory state exhibiting faster, more directed movement. Insets display the histogram of observed values (grey) and fitted distribution (black line).

Figure 3. Probability of selection for distance to water, proportion of tree cover and slope as a function of behavioural state for four representative elephants. Selection in the pooled model (solid line) differed in importance, strength and form of the selection (e.g. linear versus quadratic) from the encamped (short dashed line) and exploratory (long dashed line) behavioural state models.

Figure 4. Spatial predictions of probability of selection for one elephant (EF0197) based on the pooled (a), behaviourally averaged (b), encamped (c) and exploratory (d) habitat selection models. The black line is the seasonal range boundary based on the $95 \%$ isopleths of the kernel density estimate. 


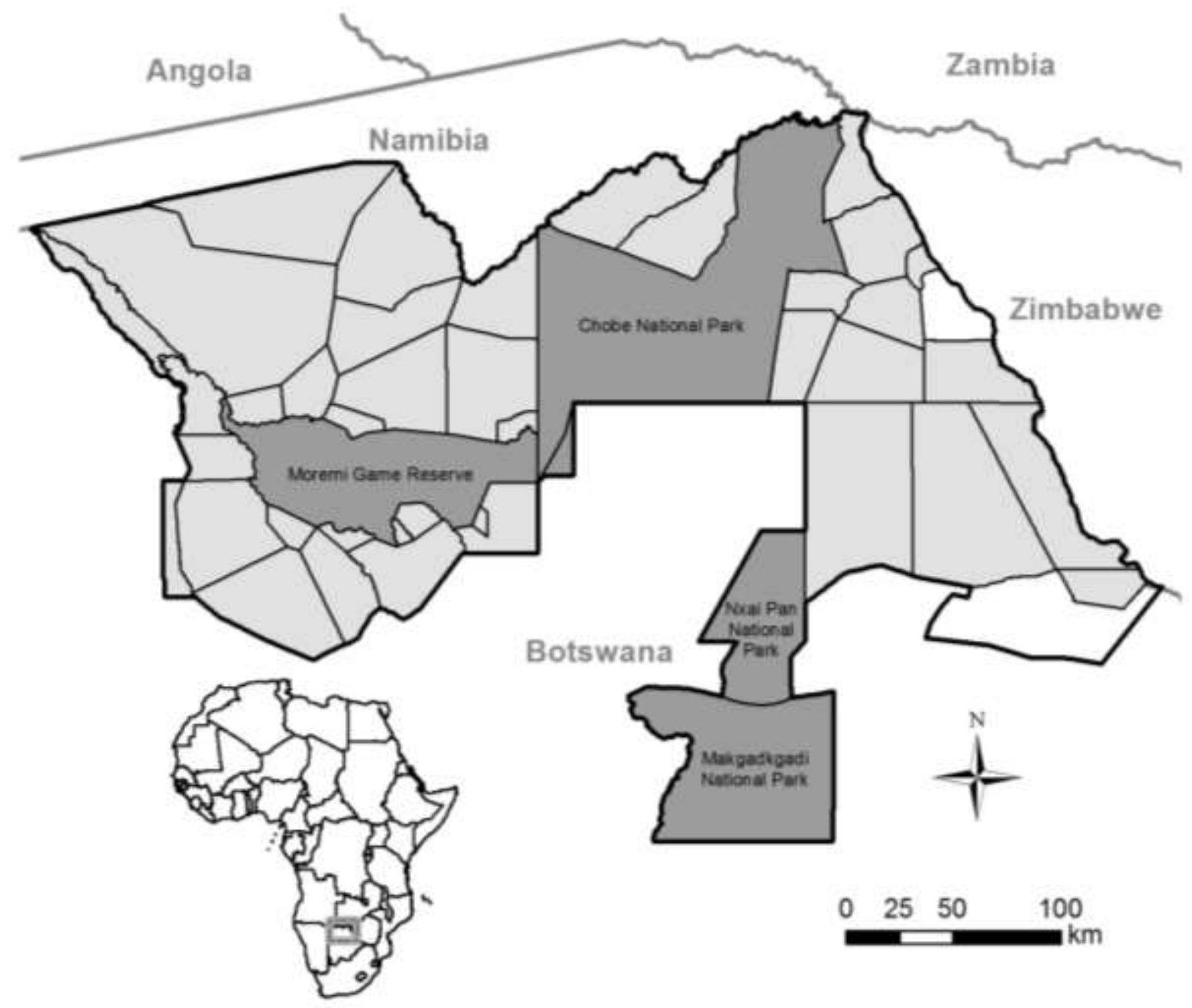

Fig. 1 


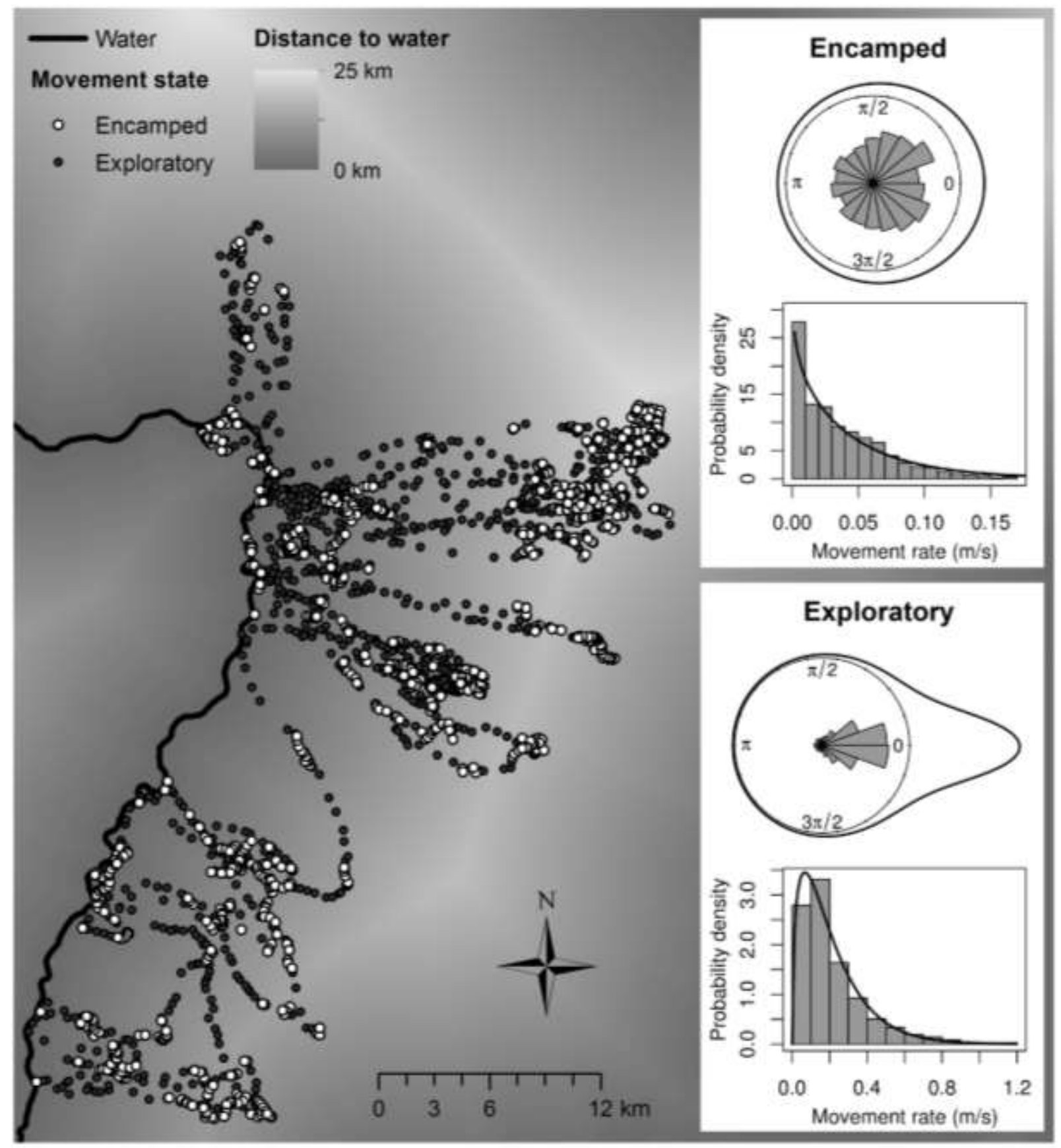

Fig. 2 

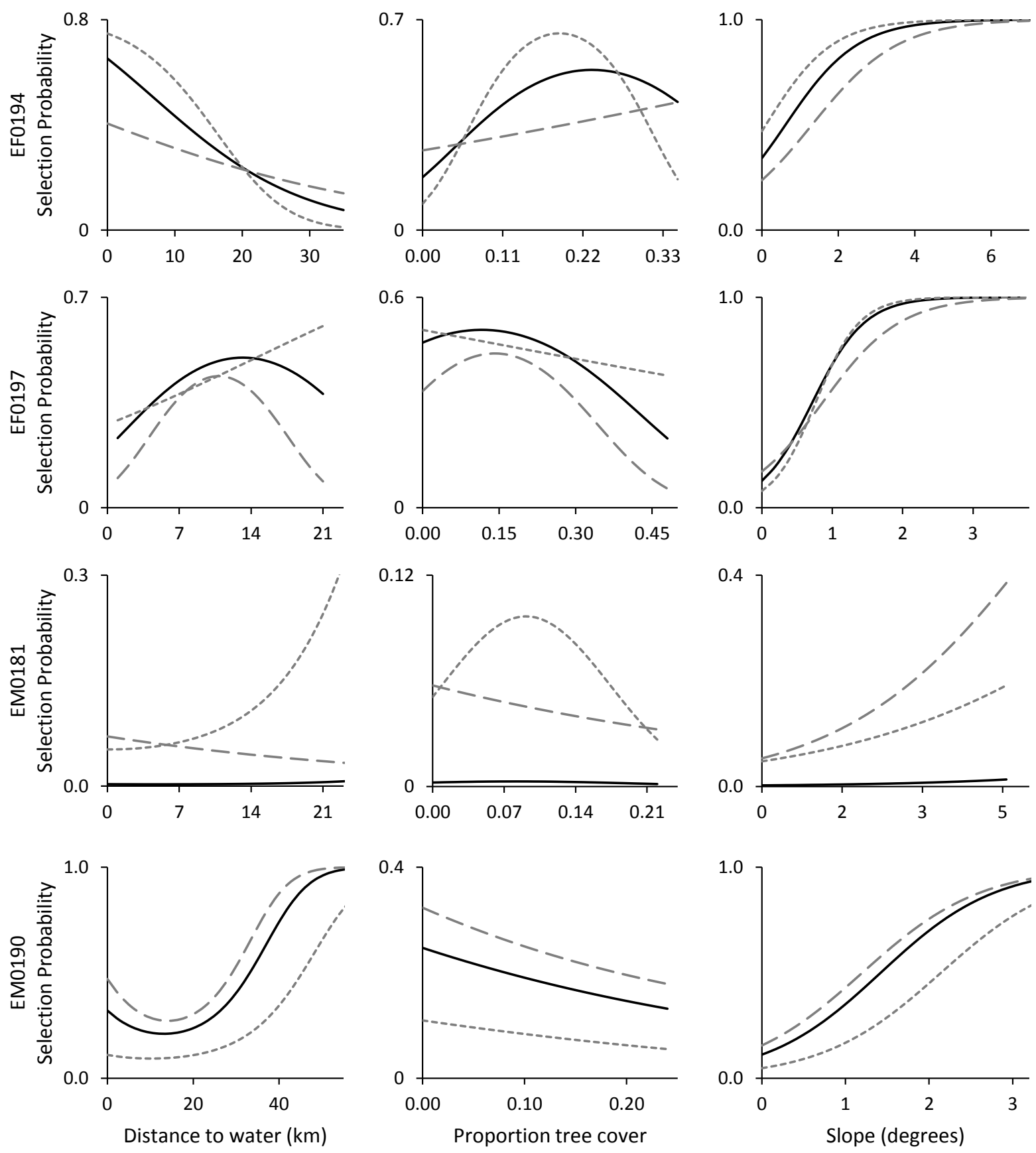

Fig. 3 

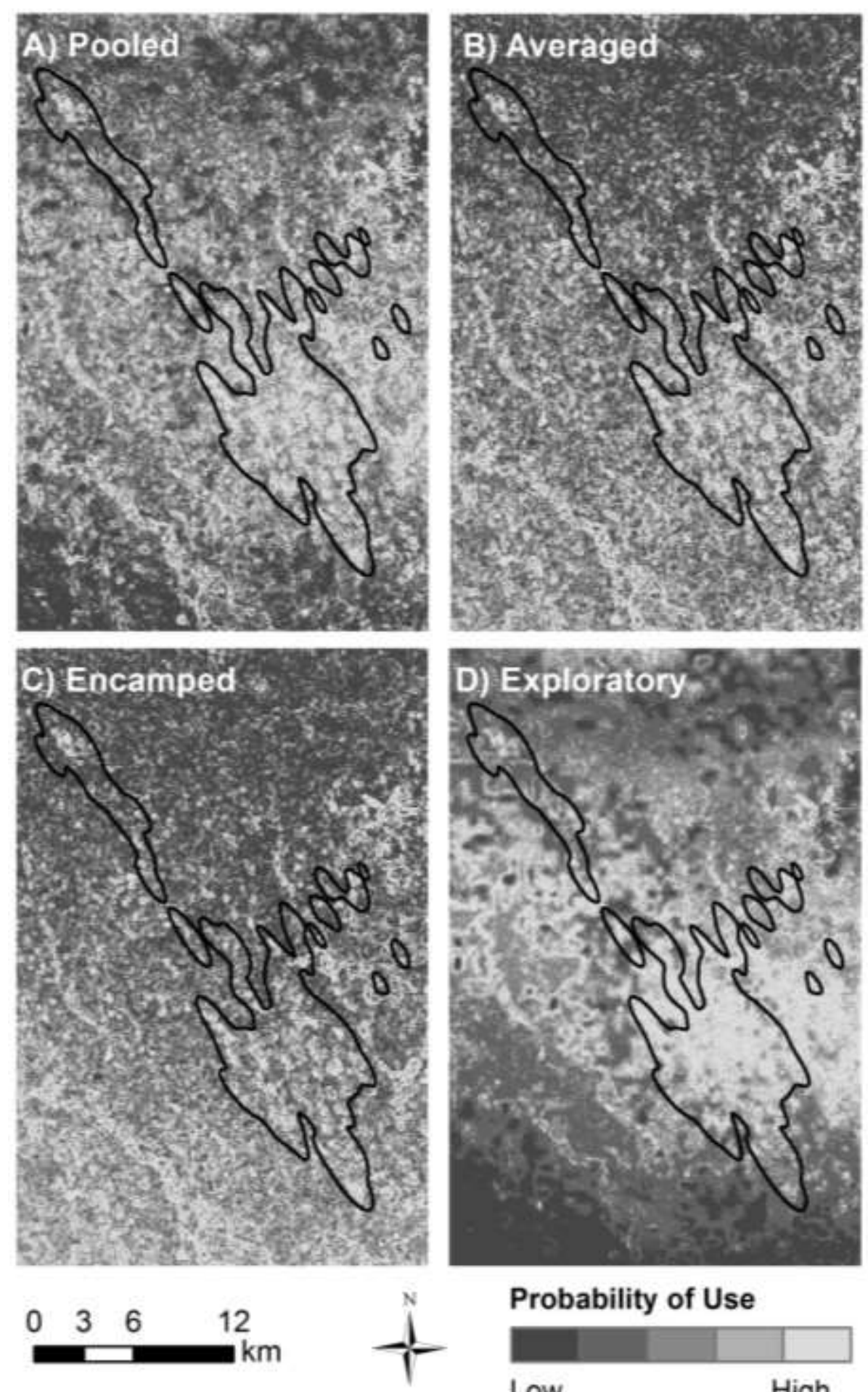

\section{Probability of Use}

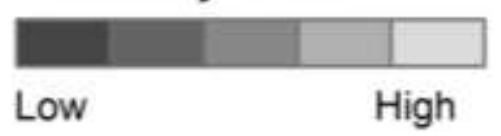

Fig. 4 


\section{Biosketch}

C.L.R, M.J.C, and R.J.v.A. are members of the Conservation Ecology Research Unit at the University of Pretoria, working to develop novel solutions to manage and maintain southern Africa's elephant population (www.ceru.up.ac.za). M.J.C is also the founder of Elephants Without Borders, a charitable organization dedicated to conserving wildlife and natural resources

(www.elephantswithoutborders.org). H.L.B. is a postdoctoral fellow with the Environmental Decisions Group at the University of Queensland and the developer of geospatial modelling environment (www.spatialecology.com). Author contributions: C.L.R. and H.L.B. conceived ideas, analysed data and led the writing; M.J.C and R.J.v.A. collected data, provided funding, and edited the manuscript. 


\section{Supporting Information}

Additional Supporting Information may be found in the online version of this article:

Appendix S1. The code and scripts used to fit the three movement models using the software JAGS.

Figure S1. Comparison of the model fit for the pooled and behaviourally averaged habitat selection models.

Figure S2. An adaption of Figure 3 with the $95 \%$ confidence intervals included.

Table S1. Summary of elephant telemetry data.

Table S2. Results of model selection to classify animal movement into discrete behavioural states.

Table S3. Estimated parameter values and convergence metrics for the state-space models.

Table S4. Full model results for the resource selection probability function (RSPF).

As a service to our authors and readers, this journal provides supporting information supplied by the authors. Such materials are peer-reviewed and may be re-organized for online delivery, but are not copy-edited or typeset. Technical support issues arising from supporting information (other than missing files) should be addressed to the authors. 


\section{Appendix S1.}

\section{Model fitting in JAGS}

Here, we reproduce the code used to fit the three movement models using JAGS. In all three models the observed data include the movement rates and turn angles characterising each step ("mr" and "ta" variables respectively). In the double and switch models the "idx" variables represents the vector of movement states.

1. The single model is a simple correlated random walk model with no behavioural states (used as a reference model):

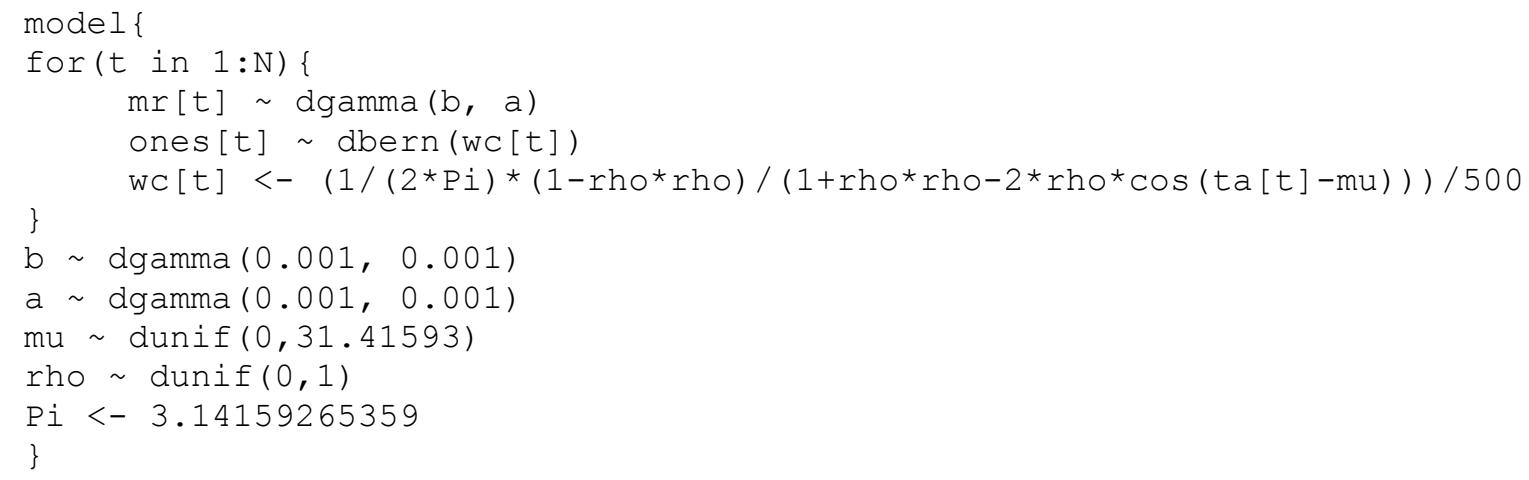

2. The double model is a combination of two random walks, each with different step length and movement rate distributions. The indices [1] and [2] correspond to parameter values associated with the first and second behavioural states respectively. There is a constant probability, $p$ (or 1-p), of being in the first (or second) state.

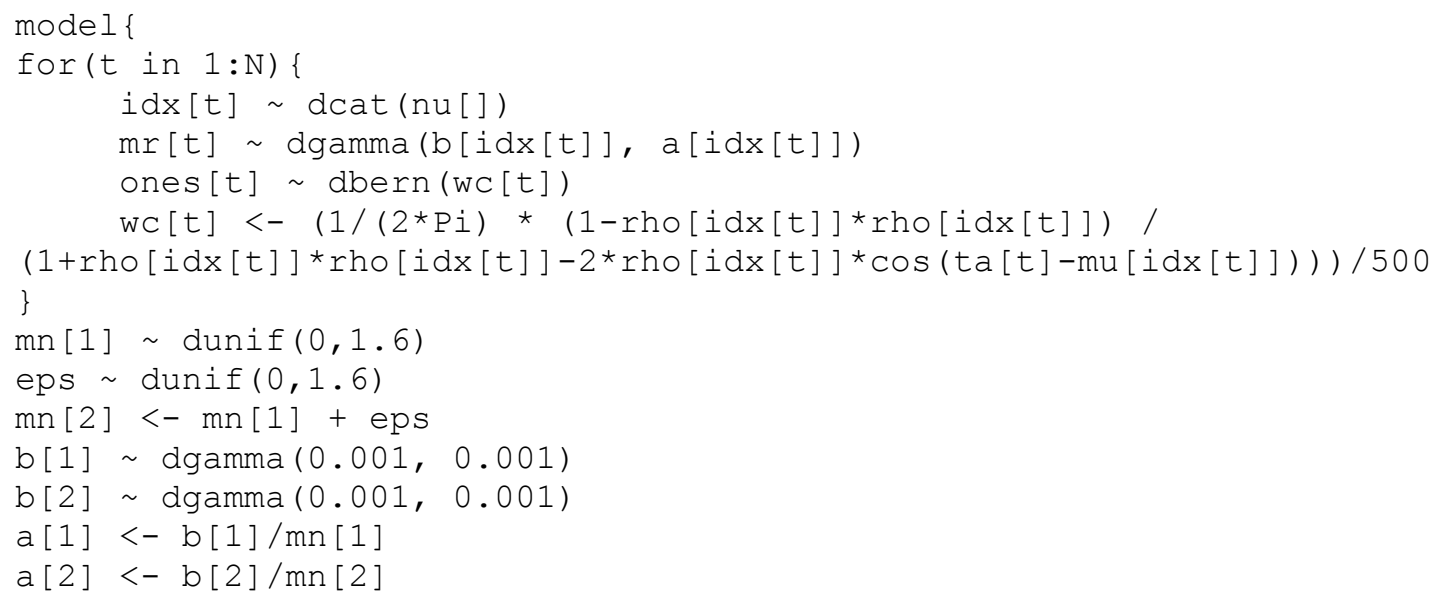




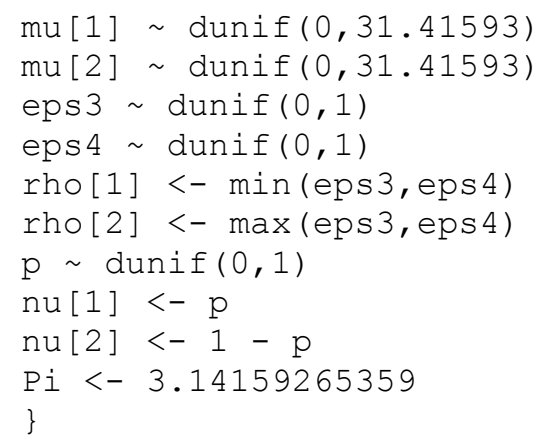

3. The switch model is also a combination of two random walks, but the probability of switching from one state to another depends on the previous behavioural state of the animal (variable $q$ ).

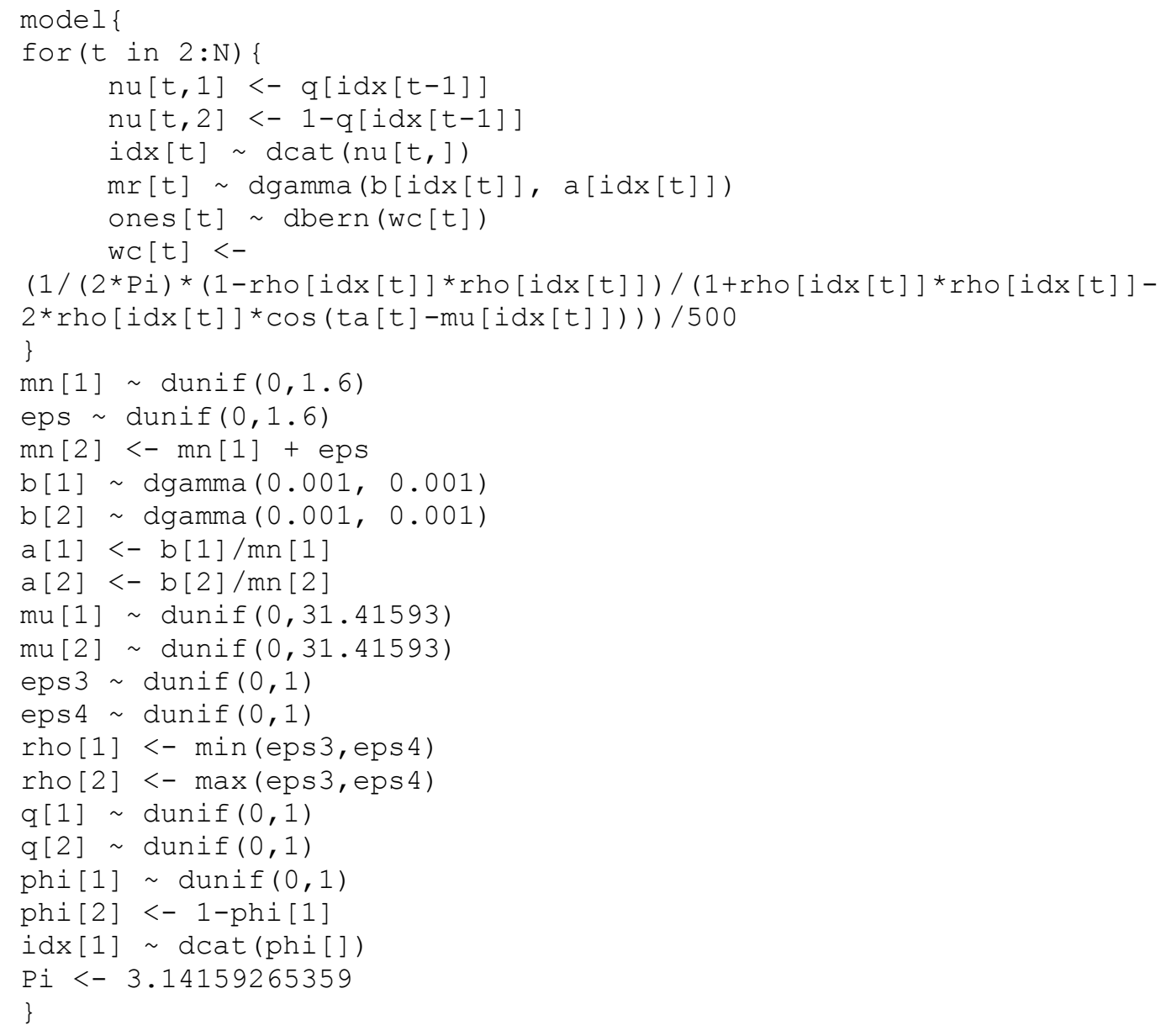

Script files were used to fit these models in JAGS. An example of a script file used to fit the double model is:

model in "m2double.txt"

data in "eledatamdoubleuidl.txt" 


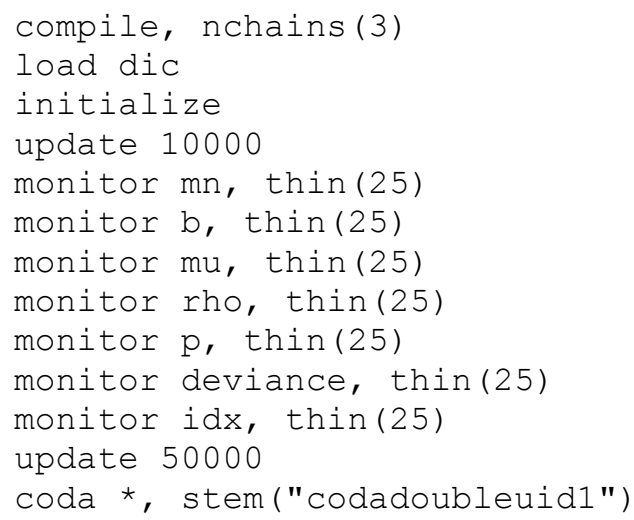

This script indicates a burn-in period of 10,000 MCMC steps, and then records parameter values over a further 50,000 MCMC steps, thinned to 1 in 25 to reduce autocorrelation in the posterior samples. 

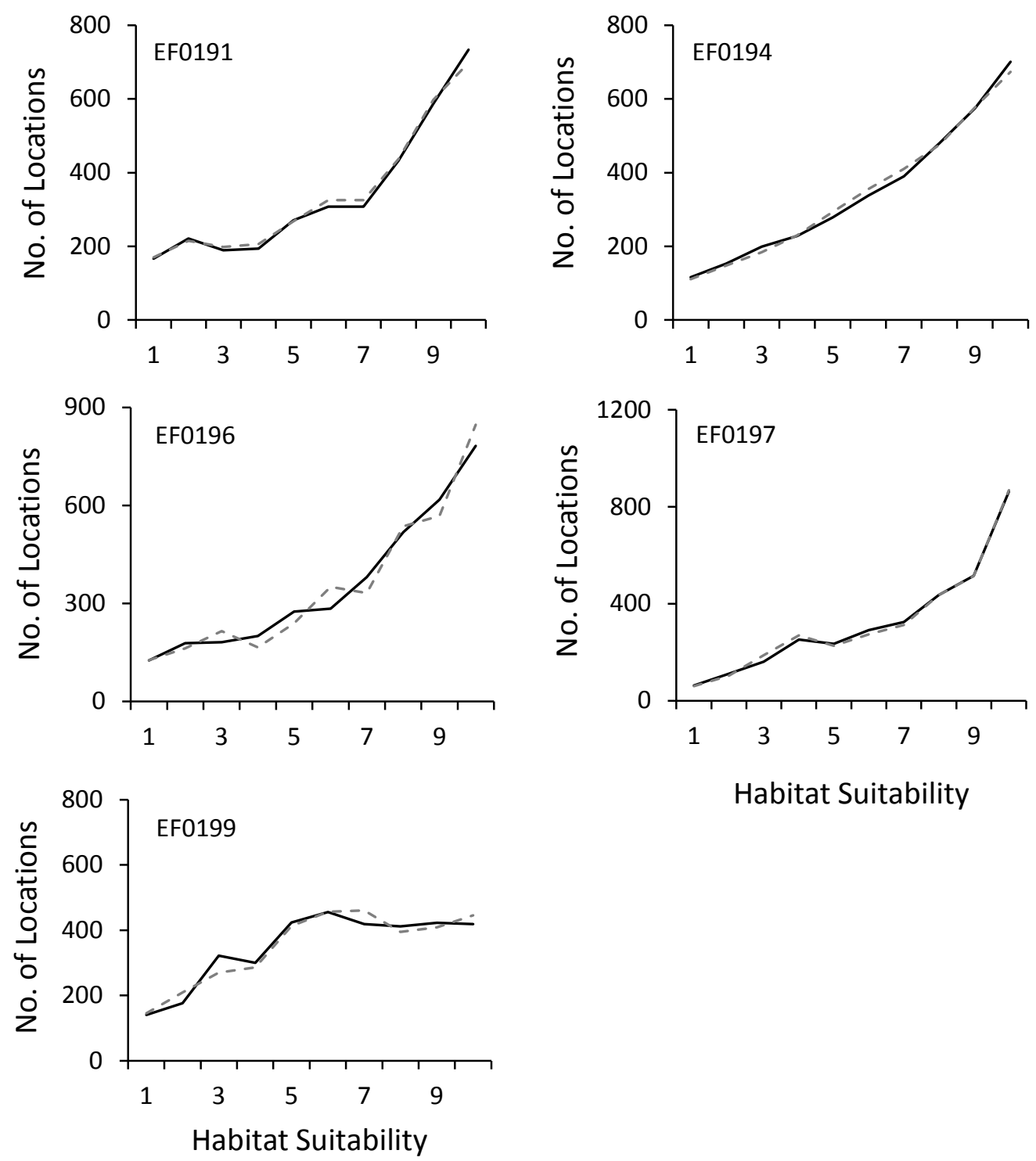

Habitat Suitability

Figure S1 (a). Comparison of the model fit for the pooled (solid line) and behaviourally averaged (dashed line) habitat selection models for female elephants. Good model fit is indicated by a greater number (No.) of elephant locations in highly suitable habitat. Fit using Spearman rank correlation coefficient was significantly increasing $\left(r_{s}=0.67, p<0.05\right)$ for all models. Model fit was similar between the pooled and averaged models. 

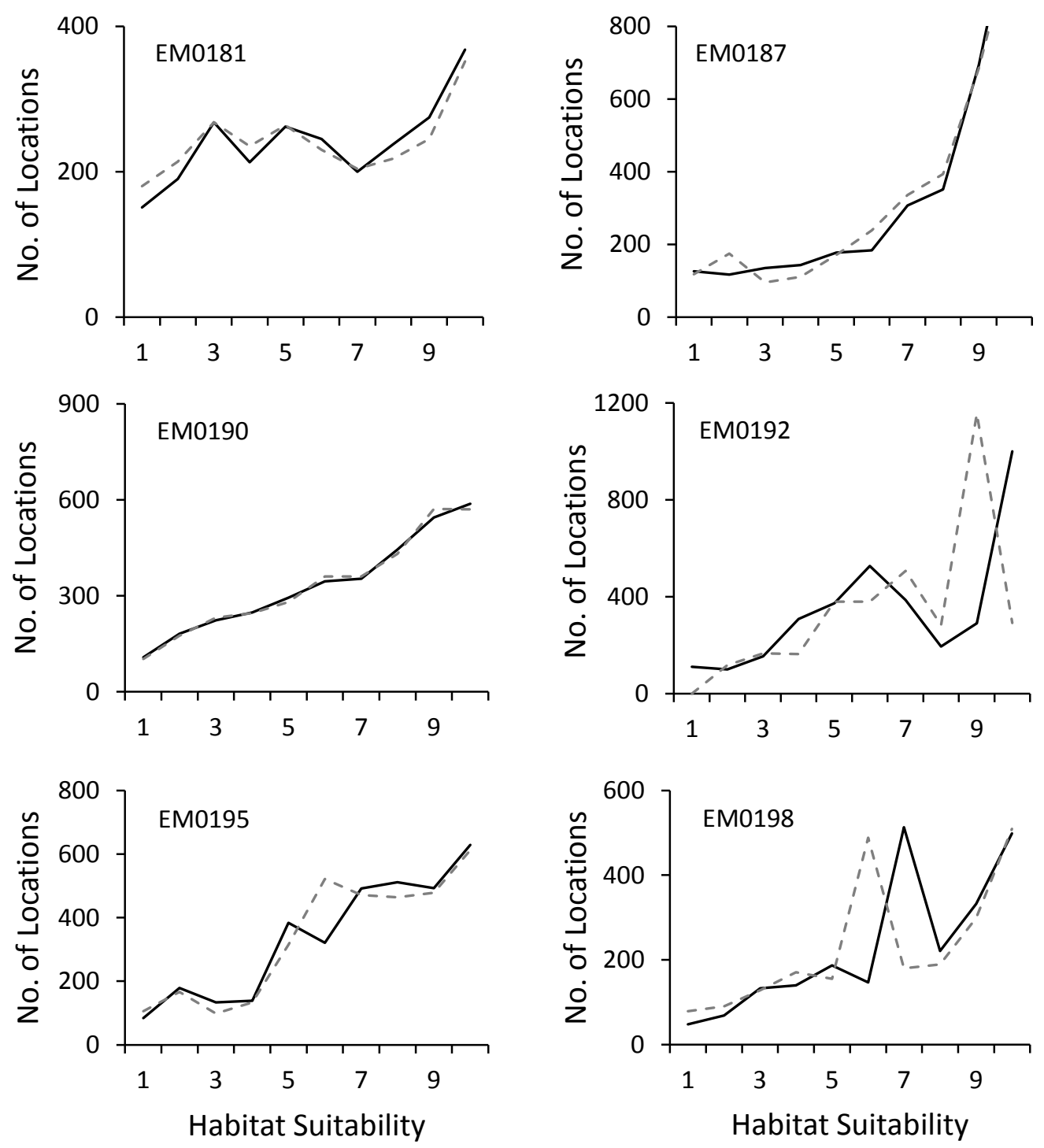

Figure S1 (b). Comparison of the model fit for the pooled (solid line) and behaviourally averaged (dashed line) habitat selection models for male elephants. Good model fit is indicated by a greater number (No.) of elephant locations in highly suitable habitat. Fit using Spearman rank correlation coefficient was significantly increasing $\left(r_{s}=0.67, p<0.05\right)$ for all models except the averaged model for EM0181 $\left(r_{s}=0.42, p=0.23\right)$. Model fit was similar between the pooled and averaged models; however, model fit was slightly better EM0181 in the pooled model and EM0192 in the behaviourally averaged model. 

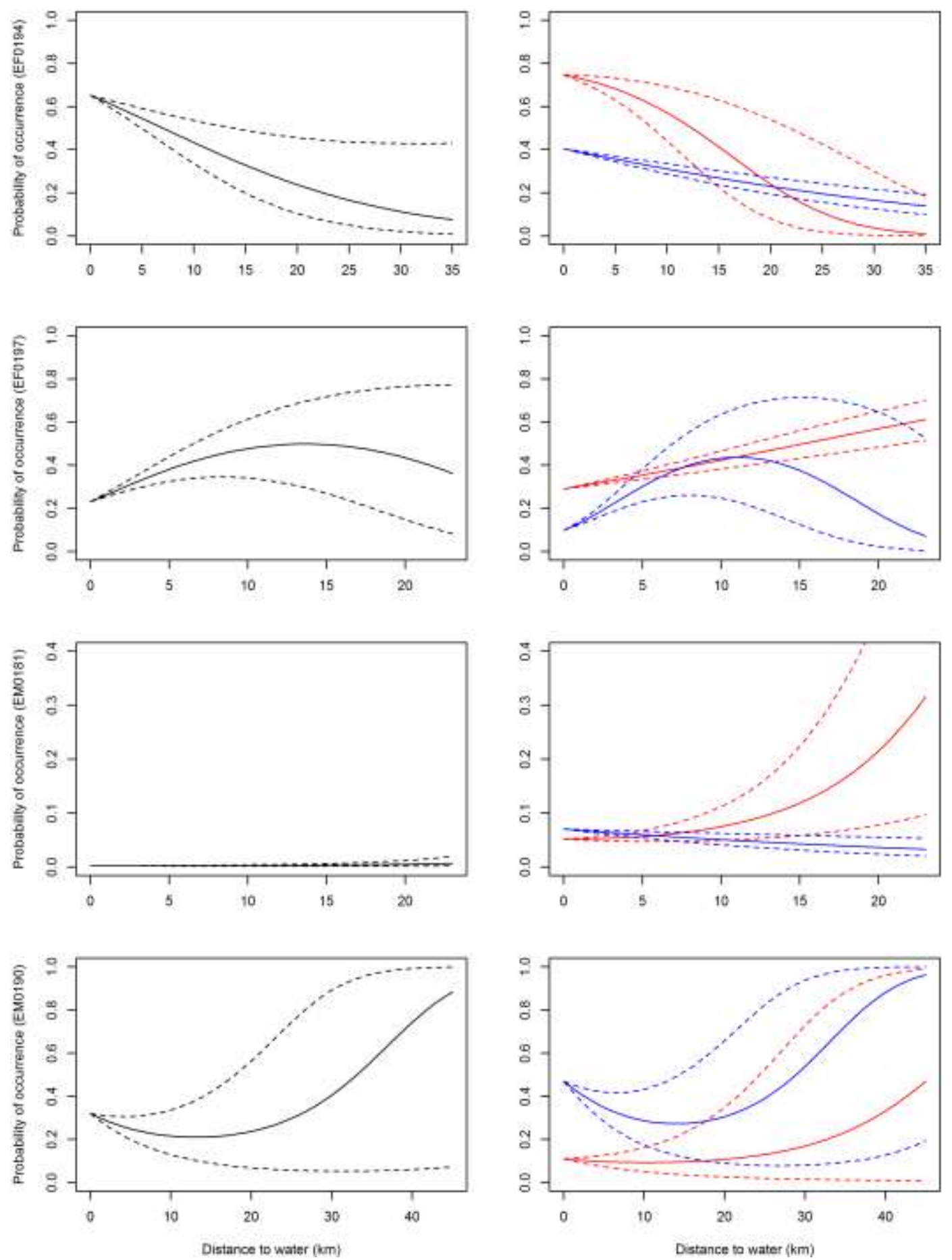

Figure S2 (a). Probability of occurrence as a function of distance to water. The black line is for the pooled model, and the red and blue lines are for the encamped and exploratory models, respectively. This is an adaptation of Figure 3 with the $95 \%$ confidence intervals included (dashed lines). 

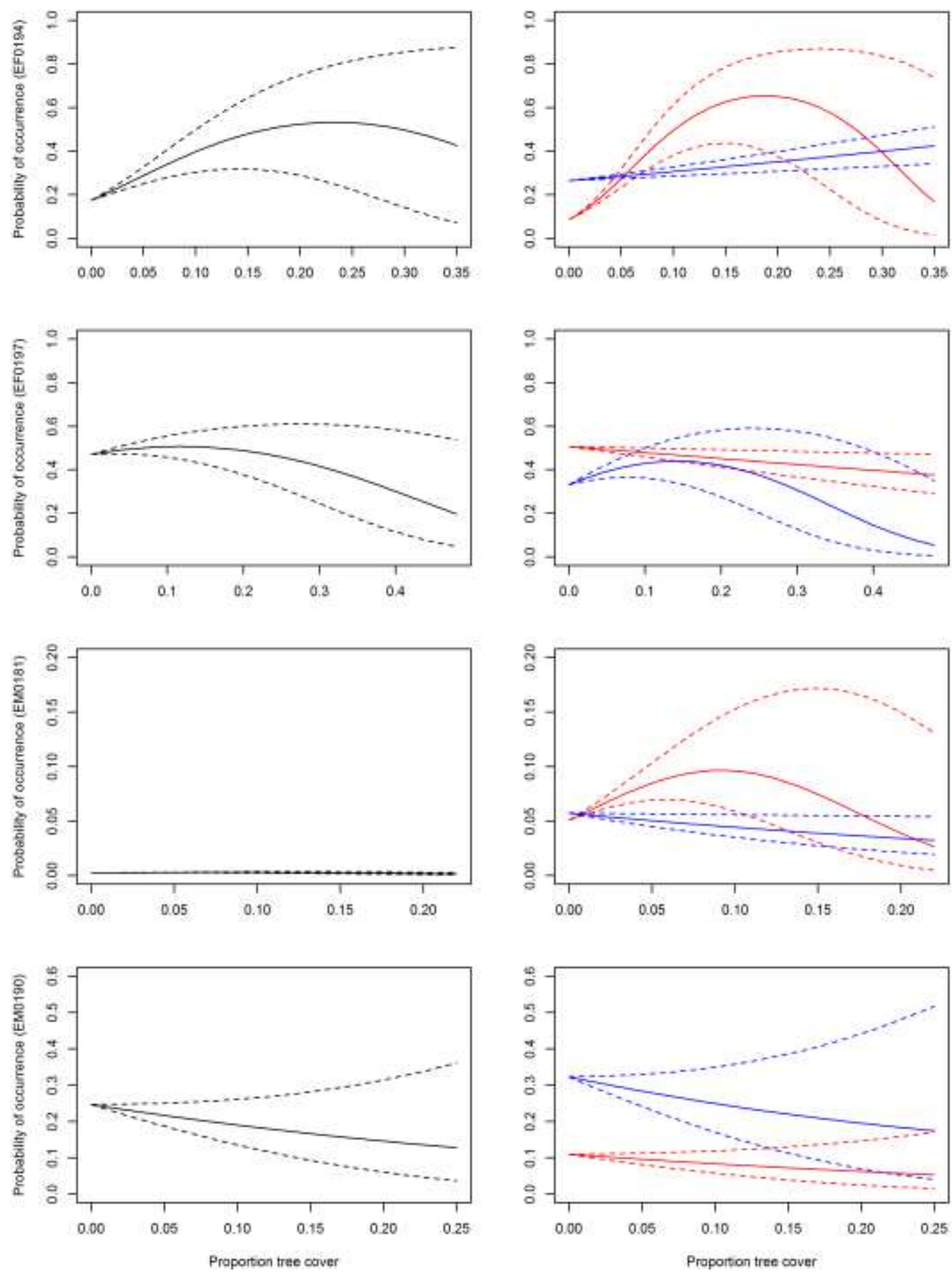

Figure S2 (b). Probability of occurrence as a function of proportion tree cover. The black line is for the pooled model, and the red and blue lines are for the encamped and exploratory models, respectively. This is an adaptation of Figure 3 with the $95 \%$ confidence intervals included (dashed lines). 

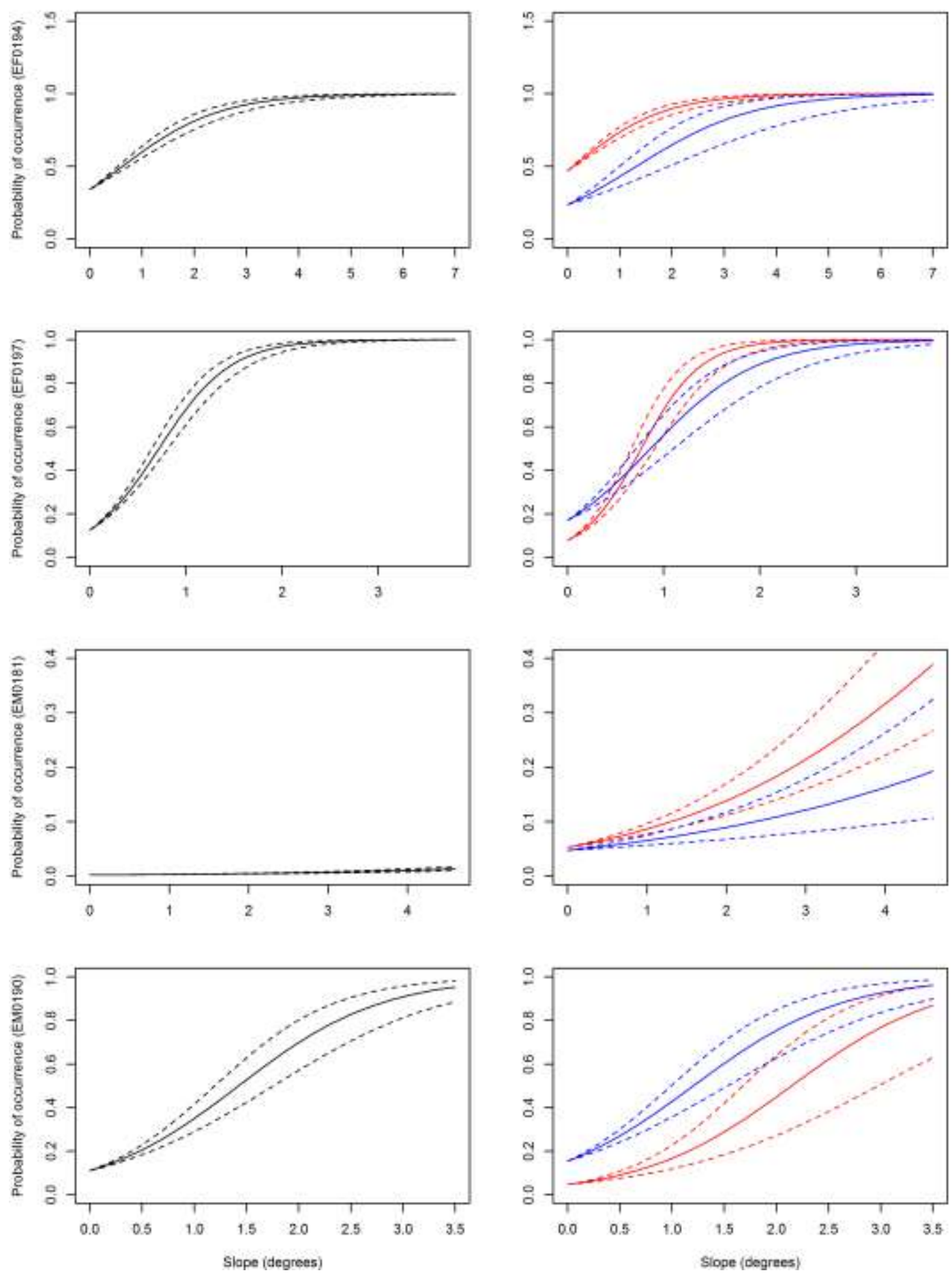

Figure S2 (c). Probability of occurrence as a function of slope. The black line is for the pooled model, and the red and blue lines are for the encamped and exploratory models, respectively. This is an adaptation of Figure 3 with the $95 \%$ confidence intervals included (dashed lines). 
Table S1. Summary of elephant telemetry data.

\begin{tabular}{llrrr}
\hline Elephant & Sex & $\begin{array}{r}\text { Home range } \\
\text { size }\left(\mathrm{km}^{2}\right)\end{array}$ & $\begin{array}{r}\text { Elephant } \\
\text { locations }\end{array}$ & $\begin{array}{r}\text { Available } \\
\text { locations }\end{array}$ \\
\hline EF0191 & $\mathrm{F}$ & 413 & 3559 & 2476 \\
EF0194 & $\mathrm{F}$ & 1714 & 3527 & 1028 \\
EF0196 & $\mathrm{F}$ & 1422 & 3601 & 8531 \\
EF0197 & $\mathrm{F}$ & 124 & 3300 & 743 \\
EF0199 & $\mathrm{F}$ & 167 & 3539 & 1004 \\
EM0181 & $\mathrm{M}$ & 245 & 1122 & 1472 \\
EM0187 & $\mathrm{M}$ & 713 & 2416 & 4278 \\
EM0190 & $\mathrm{M}$ & 465 & 3445 & 2791 \\
EM0192 & $\mathrm{M}$ & 915 & 3394 & 5490 \\
EM0195 & $\mathrm{M}$ & 647 & 3509 & 3880 \\
EM0198 & $\mathrm{M}$ & 1425 & 3416 & 8550 \\
\hline
\end{tabular}


Table S2. Results of model selection to classify animal movement into discrete behavioural states for individual elephants. The change in WAIC ( $\triangle$ WAIC) from the top model is presented.

\begin{tabular}{llrrr}
\hline & & \multicolumn{3}{c}{$\Delta$ WAIC } \\
\cline { 3 - 5 } Elephant & Sex & Single & Double & Switch \\
\hline EF0191 & $F$ & 1794.979 & 652.911 & 0 \\
EF0194 & $F$ & 3029.835 & 773.543 & 0 \\
EF0196 & $F$ & 3306.429 & 477.609 & 0 \\
EF0197 & $F$ & 2193.285 & 336.931 & 0 \\
EF0199 & $F$ & 2522.902 & 163.227 & 0 \\
EM0181 & M & 1826.146 & 204.495 & 0 \\
EM0187 & M & 1287.706 & 339.144 & 0 \\
EM0190 & $M$ & 2446.046 & 0 & 172.787 \\
EM0192 & $M$ & 2963.300 & 368.540 & 0 \\
EM0195 & $M$ & 1852.469 & 195.571 & 0 \\
EM0198 & $M$ & 1339.648 & 0 & 196.664 \\
\hline
\end{tabular}


Table S3. Estimated parameter values and convergence metrics for the top model of the state-space behaviour classification. Alpha (a) and beta (b) are the rate and shape parameters, respectively, for the turn angle distribution of the exploratory (1) and encamped (2) movement states. Mu $(\mu)$ and rho $(\rho)$ are the mean turn angle and dispersion parameters, respectively, for the wrapped Cauchy turn angle distribution. The probability of remaining in the current state(q) is present only in the switch model.

\begin{tabular}{|c|c|c|c|c|c|c|c|}
\hline Elephant & $\begin{array}{l}\text { Top } \\
\text { model }\end{array}$ & Parameter & Mean & Lower Cl & Upper Cl & $\mathrm{R}$ (hat) & $\begin{array}{l}\mathrm{R} \text { (hat) } \\
\text { Upper Cl }\end{array}$ \\
\hline \multirow[t]{11}{*}{ EF0191 } & switch & a1 & 0.041 & 0.035 & 0.048 & 0.042 & 1.001 \\
\hline & & a2 & 0.176 & 0.166 & 0.186 & 0.176 & 1.001 \\
\hline & & b1 & 0.937 & 0.861 & 1.015 & 0.938 & 1.000 \\
\hline & & b2 & 1.882 & 1.717 & 2.067 & 1.878 & 1.000 \\
\hline & & $\mu 1$ & -0.008 & -0.216 & 0.186 & -0.007 & 1.000 \\
\hline & & $\mu 2$ & 0.020 & -0.016 & 0.055 & 0.020 & 1.000 \\
\hline & & $\rho 1$ & 0.234 & 0.164 & 0.294 & 0.235 & 1.001 \\
\hline & & $\rho 2$ & 0.602 & 0.581 & 0.623 & 0.602 & 1.000 \\
\hline & & $\mathrm{q} 1$ & 0.769 & 0.726 & 0.807 & 0.770 & 1.000 \\
\hline & & $q 2$ & 0.122 & 0.099 & 0.148 & 0.122 & 1.000 \\
\hline & & deviance & 45563.424 & 45433.190 & 45695.405 & 45562.900 & 1.001 \\
\hline \multirow[t]{11}{*}{ EF0194 } & switch & a1 & 0.052 & 0.049 & 0.056 & 0.052 & 1.000 \\
\hline & & a2 & 0.296 & 0.280 & 0.312 & 0.296 & 1.001 \\
\hline & & b1 & 1.053 & 0.998 & 1.111 & 1.052 & 1.000 \\
\hline & & b2 & 2.448 & 2.191 & 2.731 & 2.442 & 1.000 \\
\hline & & $\mu 1$ & -0.010 & -0.052 & 0.031 & -0.010 & 1.000 \\
\hline & & $\mu 2$ & 0.011 & -0.008 & 0.029 & 0.011 & 1.000 \\
\hline & & $\rho 1$ & 0.531 & 0.505 & 0.555 & 0.531 & 1.000 \\
\hline & & $\rho 2$ & 0.807 & 0.793 & 0.821 & 0.807 & 1.000 \\
\hline & & $q 1$ & 0.921 & 0.906 & 0.934 & 0.921 & 1.001 \\
\hline & & $q 2$ & 0.134 & 0.112 & 0.156 & 0.133 & 1.000 \\
\hline & & deviance & 42641.734 & 42546.195 & 42740.803 & 42641.300 & 1.000 \\
\hline \multirow[t]{11}{*}{ EF0196 } & switch & a1 & 0.051 & 0.046 & 0.056 & 0.051 & 1.000 \\
\hline & & a2 & 0.302 & 0.287 & 0.318 & 0.302 & 1.000 \\
\hline & & b1 & 0.816 & 0.770 & 0.862 & 0.816 & 1.000 \\
\hline & & b2 & 2.089 & 1.904 & 2.289 & 2.087 & 1.000 \\
\hline & & $\mu 1$ & 0.001 & -0.108 & 0.108 & 0.002 & 1.000 \\
\hline & & $\mu 2$ & -0.011 & -0.033 & 0.011 & -0.012 & 1.001 \\
\hline & & $\rho 1$ & 0.284 & 0.245 & 0.321 & 0.284 & 1.000 \\
\hline & & $\rho 2$ & 0.755 & 0.738 & 0.772 & 0.755 & 1.001 \\
\hline & & q1 & 0.854 & 0.832 & 0.874 & 0.854 & 1.000 \\
\hline & & $q 2$ & 0.172 & 0.151 & 0.195 & 0.172 & 1.000 \\
\hline & & deviance & 45738.958 & 45633.393 & 45850.800 & 45738.500 & 1.001 \\
\hline
\end{tabular}


Table S3. (cont.)

\begin{tabular}{|c|c|c|c|c|c|c|c|}
\hline Elephant & $\begin{array}{l}\text { Top } \\
\text { model }\end{array}$ & Parameter & Mean & Lower $\mathrm{Cl}$ & Upper Cl & $\mathrm{R}$ (hat) & $\begin{array}{l}\mathrm{R} \text { (hat) } \\
\text { Upper Cl }\end{array}$ \\
\hline \multirow[t]{11}{*}{ EF0197 } & switch & a1 & 0.016 & 0.015 & 0.017 & 0.016 & 1.001 \\
\hline & & a2 & 0.076 & 0.071 & 0.081 & 0.076 & 1.001 \\
\hline & & b1 & 1.612 & 1.486 & 1.746 & 1.611 & 1.000 \\
\hline & & b2 & 1.474 & 1.325 & 1.644 & 1.470 & 1.000 \\
\hline & & $\mu 1$ & 1.137 & 0.704 & 1.615 & 1.134 & 1.001 \\
\hline & & $\mu 2$ & 0.017 & -0.047 & 0.080 & 0.017 & 1.000 \\
\hline & & $\rho 1$ & 0.100 & 0.063 & 0.136 & 0.100 & 1.002 \\
\hline & & $\rho 2$ & 0.487 & 0.457 & 0.519 & 0.488 & 1.000 \\
\hline & & $q 1$ & 0.830 & 0.802 & 0.856 & 0.830 & 1.001 \\
\hline & & q2 & 0.183 & 0.151 & 0.217 & 0.183 & 1.000 \\
\hline & & deviance & 36051.166 & 35899.500 & 36206.200 & 36050.150 & 1.004 \\
\hline \multirow[t]{11}{*}{ EF0199 } & switch & a1 & 0.021 & 0.019 & 0.023 & 0.021 & 1.002 \\
\hline & & a2 & 0.115 & 0.108 & 0.123 & 0.115 & 1.001 \\
\hline & & b1 & 0.996 & 0.932 & 1.067 & 0.995 & 1.000 \\
\hline & & b2 & 1.609 & 1.448 & 1.786 & 1.607 & 1.000 \\
\hline & & $\mu 1$ & -0.064 & -0.319 & 0.189 & -0.061 & 1.000 \\
\hline & & $\mu 2$ & 0.033 & -0.005 & 0.071 & 0.033 & 1.000 \\
\hline & & $\rho 1$ & 0.145 & 0.102 & 0.188 & 0.145 & 1.000 \\
\hline & & $\rho 2$ & 0.627 & 0.604 & 0.651 & 0.627 & 1.000 \\
\hline & & $q 1$ & 0.834 & 0.804 & 0.860 & 0.834 & 1.000 \\
\hline & & $q 2$ & 0.177 & 0.150 & 0.205 & 0.176 & 1.000 \\
\hline & & deviance & 40405.427 & 40241.095 & 40570.303 & 40404.550 & 1.001 \\
\hline \multirow[t]{11}{*}{ EM0181 } & switch & a1 & 0.048 & 0.044 & 0.053 & 0.048 & 1.002 \\
\hline & & a2 & 0.237 & 0.220 & 0.255 & 0.237 & 1.000 \\
\hline & & b1 & 0.928 & 0.862 & 0.995 & 0.929 & 1.000 \\
\hline & & b2 & 1.807 & 1.610 & 2.035 & 1.803 & 1.001 \\
\hline & & $\mu 1$ & 0.026 & -0.074 & 0.123 & 0.026 & 1.000 \\
\hline & & $\mu 2$ & -0.011 & -0.035 & 0.013 & -0.011 & 1.000 \\
\hline & & $\rho 1$ & 0.349 & 0.296 & 0.398 & 0.350 & 1.001 \\
\hline & & $\rho 2$ & 0.783 & 0.764 & 0.801 & 0.783 & 1.000 \\
\hline & & q1 & 0.872 & 0.844 & 0.898 & 0.873 & 1.002 \\
\hline & & $q 2$ & 0.164 & 0.136 & 0.193 & 0.164 & 1.000 \\
\hline & & deviance & 29710.592 & 29615.593 & 29811.303 & 29710.200 & 1.001 \\
\hline
\end{tabular}


Table S3. (cont.)

\begin{tabular}{|c|c|c|c|c|c|c|c|}
\hline Elephant & $\begin{array}{l}\text { Top } \\
\text { model }\end{array}$ & Parameter & Mean & Lower Cl & Upper Cl & $\mathrm{R}$ (hat) & $\begin{array}{l}\mathrm{R} \text { (hat) } \\
\text { Upper Cl }\end{array}$ \\
\hline \multirow[t]{11}{*}{ EM0187 } & switch & a1 & 0.050 & 0.045 & 0.054 & 0.050 & 1.000 \\
\hline & & a2 & 0.168 & 0.153 & 0.186 & 0.168 & 1.000 \\
\hline & & b1 & 0.995 & 0.941 & 1.049 & 0.995 & 1.000 \\
\hline & & b2 & 1.639 & 1.457 & 1.845 & 1.635 & 1.001 \\
\hline & & $\mu 1$ & 0.059 & -0.091 & 0.220 & 0.057 & 1.000 \\
\hline & & $\mu 2$ & -0.042 & -0.095 & 0.011 & -0.042 & 1.000 \\
\hline & & $\rho 1$ & 0.201 & 0.164 & 0.236 & 0.202 & 1.000 \\
\hline & & $\rho 2$ & 0.612 & 0.571 & 0.653 & 0.612 & 1.000 \\
\hline & & q1 & 0.916 & 0.890 & 0.939 & 0.917 & 1.000 \\
\hline & & $q 2$ & 0.194 & 0.154 & 0.235 & 0.193 & 1.003 \\
\hline & & deviance & 42864.441 & 42722.895 & 43006.803 & 42863.650 & 1.001 \\
\hline \multirow[t]{10}{*}{ EM0190 } & double & a1 & 0.019 & 0.014 & 0.024 & 0.018 & 1.006 \\
\hline & & a2 & 0.139 & 0.126 & 0.152 & 0.138 & 1.005 \\
\hline & & b1 & 0.962 & 0.869 & 1.080 & 0.957 & 1.001 \\
\hline & & b2 & 1.576 & 1.276 & 1.892 & 1.574 & 1.004 \\
\hline & & $\mu 1$ & 2.383 & -3.003 & 3.077 & 2.655 & 1.001 \\
\hline & & $\mu 2$ & 0.012 & -0.048 & 0.072 & 0.011 & 1.002 \\
\hline & & $\rho 1$ & 0.090 & 0.024 & 0.170 & 0.088 & 1.003 \\
\hline & & $\rho 2$ & 0.448 & 0.410 & 0.487 & 0.448 & 1.001 \\
\hline & & $p$ & 0.370 & 0.285 & 0.450 & 0.372 & 1.006 \\
\hline & & deviance & 41711.325 & 41461.988 & 42041.125 & 41697.400 & 1.002 \\
\hline \multirow[t]{11}{*}{ EM0192 } & switch & a1 & 0.036 & 0.033 & 0.039 & 0.036 & 1.001 \\
\hline & & a2 & 0.232 & 0.215 & 0.251 & 0.232 & 1.002 \\
\hline & & b1 & 0.942 & 0.891 & 0.995 & 0.941 & 1.000 \\
\hline & & b2 & 1.498 & 1.346 & 1.664 & 1.495 & 1.000 \\
\hline & & $\mu 1$ & 0.096 & 0.028 & 0.164 & 0.095 & 1.000 \\
\hline & & $\mu 2$ & 0.015 & -0.006 & 0.036 & 0.015 & 1.000 \\
\hline & & $\rho 1$ & 0.385 & 0.349 & 0.419 & 0.386 & 1.000 \\
\hline & & $\rho 2$ & 0.797 & 0.780 & 0.813 & 0.797 & 1.001 \\
\hline & & $q 1$ & 0.897 & 0.877 & 0.915 & 0.898 & 1.002 \\
\hline & & $q 2$ & 0.177 & 0.151 & 0.204 & 0.176 & 1.002 \\
\hline & & deviance & 41391.126 & 41281.190 & 41505.705 & 41390.400 & 1.002 \\
\hline
\end{tabular}


Table S3. (cont.)

\begin{tabular}{|c|c|c|c|c|c|c|c|}
\hline Elephant & $\begin{array}{l}\text { Top } \\
\text { model } \\
\end{array}$ & Parameter & Mean & Lower $\mathrm{Cl}$ & Upper Cl & $\mathrm{R}$ (hat) & $\begin{array}{l}\mathrm{R} \text { (hat) } \\
\text { Upper Cl }\end{array}$ \\
\hline \multirow[t]{10}{*}{ EM0195 } & double & a1 & 0.005 & 0.005 & 0.006 & 0.005 & 1.000 \\
\hline & & a2 & 0.105 & 0.100 & 0.110 & 0.105 & 1.003 \\
\hline & & b1 & 2.043 & 1.656 & 2.478 & 2.034 & 1.000 \\
\hline & & $\mathrm{b} 2$ & 0.845 & 0.797 & 0.896 & 0.844 & 1.001 \\
\hline & & $\mu 1$ & -0.273 & -3.134 & 3.135 & -2.909 & 1.000 \\
\hline & & $\mu 2$ & -0.037 & -0.089 & 0.013 & -0.037 & 1.000 \\
\hline & & $\rho 1$ & 0.291 & 0.208 & 0.375 & 0.291 & 1.000 \\
\hline & & $\rho 2$ & 0.435 & 0.413 & 0.457 & 0.435 & 1.000 \\
\hline & & $p$ & 0.148 & 0.125 & 0.172 & 0.148 & 1.000 \\
\hline & & deviance & 41905.882 & 41725.298 & 42089.005 & 41903.400 & 1.002 \\
\hline \multirow[t]{10}{*}{ EM0198 } & double & a1 & 0.007 & 0.006 & 0.008 & 0.007 & 1.001 \\
\hline & & a2 & 0.074 & 0.070 & 0.079 & 0.074 & 1.001 \\
\hline & & b1 & 1.424 & 1.189 & 1.698 & 1.419 & 1.000 \\
\hline & & b2 & 1.025 & 0.938 & 1.126 & 1.023 & 1.001 \\
\hline & & $\mu 1$ & 2.597 & -3.117 & 3.123 & 2.977 & 1.008 \\
\hline & & $\mu 2$ & -0.075 & -0.146 & -0.003 & -0.075 & 1.001 \\
\hline & & $\rho 1$ & 0.338 & 0.251 & 0.401 & 0.341 & 1.000 \\
\hline & & $\rho 2$ & 0.406 & 0.375 & 0.437 & 0.406 & 1.000 \\
\hline & & $p$ & 0.217 & 0.183 & 0.256 & 0.216 & 1.001 \\
\hline & & deviance & 26653.950 & 26491.693 & 26815.503 & 26654.600 & 1.000 \\
\hline
\end{tabular}


Table S4. Full model results for the resource selection probability function (RSPF) for each individual and behavioural state.

\begin{tabular}{|c|c|c|c|c|c|c|c|c|c|}
\hline \multirow[b]{3}{*}{ EF0191 } & \multicolumn{3}{|c|}{ Pooled } & \multicolumn{3}{|c|}{ Encamped } & \multicolumn{3}{|c|}{ Exploratory } \\
\hline & Beta & \multicolumn{2}{|l|}{ SE } & Beta & \multicolumn{2}{|l|}{ SE } & Beta & \multicolumn{2}{|l|}{ SE } \\
\hline & & & & & & & & & \\
\hline (Intercept) & -12.695 & 5.819 & $*$ & -46.050 & 0.292 & $*$ & -17.183 & 2.718 & * \\
\hline water & -0.099 & 0.041 & $*$ & -0.039 & 0.037 & & -0.198 & 0.036 & $*$ \\
\hline$(\text { water })^{2} \dagger$ & 0.418 & 0.710 & & -0.701 & 0.823 & & 2.516 & 0.605 & * \\
\hline tree & -5.362 & 1.223 & $*$ & -0.917 & 0.366 & $*$ & -8.116 & 0.664 & $*$ \\
\hline$(\text { tree })^{2}$ & -4.151 & 5.869 & & -25.742 & 1.634 & $*$ & 5.621 & 2.291 & * \\
\hline human & 0.557 & 0.100 & $*$ & 1.065 & 0.033 & $*$ & 0.671 & 0.041 & $*$ \\
\hline$(\text { human })^{2} \dagger$ & -0.766 & 0.128 & * & -1.424 & 0.045 & $*$ & -0.904 & 0.053 & * \\
\hline \multicolumn{10}{|l|}{ EF0194 } \\
\hline (Intercept) & -1.304 & 0.158 & $*$ & -2.274 & 0.160 & $*$ & -1.109 & 0.188 & * \\
\hline water & -0.090 & 0.020 & $*$ & -0.048 & 0.024 & $*$ & -0.041 & 0.006 & * \\
\hline$(\text { water })^{2} \dagger$ & 0.001 & 0.063 & & -0.322 & 0.086 & $*$ & & & \\
\hline tree & 14.432 & 1.981 & $*$ & 31.813 & 2.268 & $*$ & 2.051 & 0.537 & $*$ \\
\hline$(\text { tree })^{2}$ & -31.046 & 6.542 & * & -84.724 & 7.368 & $*$ & & & \\
\hline slope & 1.062 & 0.092 & $*$ & 1.149 & 0.106 & $*$ & 0.893 & 0.154 & $*$ \\
\hline \multicolumn{10}{|l|}{ EF0196 } \\
\hline (Intercept) & -8.199 & 1.224 & $*$ & -14.276 & 1.779 & $*$ & -6.928 & 1.096 & $*$ \\
\hline water & -0.004 & 0.008 & & -0.009 & 0.010 & & 0.006 & 0.010 & \\
\hline$(\text { water })^{2} \dagger$ & -0.039 & 0.022 & & -0.010 & 0.028 & & -0.066 & 0.029 & * \\
\hline tree & 7.342 & 0.378 & $*$ & 8.391 & 0.592 & $*$ & 4.897 & 0.583 & $*$ \\
\hline$(\text { tree })^{2}$ & -14.044 & 1.444 & $*$ & -11.538 & 2.302 & $*$ & -12.242 & 2.236 & $*$ \\
\hline slope & 0.384 & 0.015 & $*$ & 0.415 & 0.026 & $*$ & 0.363 & 0.035 & $*$ \\
\hline human & 0.138 & 0.009 & $*$ & 0.173 & 0.012 & $*$ & 0.117 & 0.013 & $*$ \\
\hline (human) $)^{2} \dagger$ & -0.295 & 0.024 & * & -0.381 & 0.030 & $*$ & -0.244 & 0.034 & * \\
\hline \multicolumn{10}{|l|}{ EF0197 } \\
\hline (Intercept) & -3.206 & 0.144 & $*$ & -2.968 & 0.150 & $*$ & -3.927 & 0.214 & $*$ \\
\hline water & 0.175 & 0.025 & $*$ & 0.059 & 0.009 & $*$ & 0.355 & 0.037 & * \\
\hline$(\text { water })^{2} \dagger$ & -0.639 & 0.116 & * & & & & -1.608 & 0.172 & $*$ \\
\hline tree & 2.513 & 0.986 & $*$ & -1.107 & 0.430 & $*$ & 6.451 & 1.406 & $*$ \\
\hline$(\text { tree })^{2}$ & -10.810 & 2.361 & $*$ & & & & -22.791 & 3.414 & $*$ \\
\hline slope & 2.683 & 0.166 & $*$ & 3.205 & 0.267 & $*$ & 1.820 & 0.212 & $*$ \\
\hline
\end{tabular}

$\dagger$ Coefficients and standard errors were multiplied by 100 . 
Table S4. (cont.)

\begin{tabular}{|c|c|c|c|c|c|c|c|c|c|}
\hline \multirow[b]{3}{*}{ EF0199 } & \multicolumn{3}{|c|}{ Pooled } & \multicolumn{3}{|c|}{ Encamped } & \multicolumn{3}{|c|}{ Exploratory } \\
\hline & \multirow[t]{2}{*}{ Beta } & \multicolumn{2}{|l|}{ SE } & \multirow[t]{2}{*}{ Beta } & \multicolumn{2}{|l|}{ SE } & \multirow[t]{2}{*}{ Beta } & \multicolumn{2}{|l|}{ SE } \\
\hline & & & & & & & & & \\
\hline (Intercept) & 1.237 & 0.214 & & -1.185 & 3.331 & & 0.585 & 0.221 & * \\
\hline water & 0.046 & 0.029 & $*$ & 0.074 & 0.081 & & 0.153 & 0.034 & * \\
\hline$(\text { water })^{2} \dagger$ & & & & -0.779 & 0.396 & $*$ & & & \\
\hline tree & -8.339 & 0.725 & $*$ & -0.500 & 2.160 & & -8.583 & 0.712 & * \\
\hline$(\text { tree })^{2}$ & & & & -5.040 & 5.078 & & & & \\
\hline slope & 1.674 & 0.287 & $*$ & 0.694 & 0.438 & & 0.797 & 0.161 & $*$ \\
\hline \multicolumn{10}{|l|}{ EM0181 } \\
\hline (Intercept) & -6.485 & 3.526 & & -3.576 & 1.795 & $*$ & -2.667 & 3.472 & \\
\hline water & -0.028 & 0.016 & & -0.002 & 0.019 & & -0.035 & 0.012 & $*$ \\
\hline$(\text { water })^{2} \dagger$ & 0.301 & 0.070 & $*$ & 0.410 & 0.098 & $*$ & & & \\
\hline tree & 6.068 & 0.794 & $*$ & 15.105 & 2.118 & $*$ & -2.714 & 1.296 & * \\
\hline$(\text { tree })^{2}$ & -37.361 & 4.548 & $*$ & -82.541 & 13.239 & $*$ & & & \\
\hline slope & 0.405 & 0.033 & $*$ & 0.528 & 0.065 & $*$ & 0.340 & 0.081 & $*$ \\
\hline human & 0.106 & 0.026 & $*$ & 0.084 & 0.034 & $*$ & & & \\
\hline (human) $)^{2} \dagger$ & -1.119 & 0.218 & $*$ & -0.966 & 0.315 & $*$ & & & \\
\hline \multicolumn{10}{|l|}{ EM0187 } \\
\hline (Intercept) & -7.120 & 7.617 & & -18.697 & 5.875 & $*$ & -1.350 & 3.828 & \\
\hline water & -0.414 & 0.009 & $*$ & -0.542 & 0.011 & $*$ & -0.174 & 0.061 & * \\
\hline$(\text { water })^{2} \dagger$ & 1.892 & 0.050 & $*$ & 2.386 & 0.065 & $*$ & 0.906 & 0.359 & * \\
\hline tree & -8.037 & 0.546 & $*$ & -8.793 & 0.708 & $*$ & -6.294 & 6.464 & \\
\hline$(\text { tree })^{2}$ & 13.822 & 2.347 & $*$ & 14.040 & 3.037 & $*$ & 12.190 & 18.840 & \\
\hline slope & -0.087 & 0.025 & $*$ & -0.152 & 0.016 & $*$ & 0.048 & 0.061 & \\
\hline \multicolumn{10}{|l|}{ EM0190 } \\
\hline (Intercept) & -1.309 & 0.428 & $*$ & -2.639 & 0.872 & $*$ & -0.631 & 0.425 & \\
\hline water & -0.087 & 0.030 & $*$ & -0.037 & 0.032 & & -0.123 & 0.032 & * \\
\hline$(\text { water })^{2} \dagger$ & 0.329 & 0.082 & $*$ & 0.183 & 0.083 & & 0.436 & 0.084 & $*$ \\
\hline tree & -3.403 & 1.935 & & -2.863 & 1.841 & & -3.841 & 2.237 & \\
\hline$(\text { tree })^{2}$ & 0.787 & 6.418 & & -1.004 & 6.224 & & 2.343 & 7.843 & \\
\hline slope & 1.459 & 0.150 & $*$ & 1.399 & 0.209 & $*$ & 1.409 & 0.162 & $*$ \\
\hline
\end{tabular}

$\dagger$ Coefficients and standard errors were multiplied by 100 . 
Table S4. (cont.)

\begin{tabular}{|c|c|c|c|c|c|c|c|c|c|}
\hline \multirow{2}{*}{ EM0192 } & \multicolumn{3}{|l|}{ Pooled } & \multicolumn{3}{|c|}{ Encamped } & \multicolumn{3}{|c|}{ Exploratory } \\
\hline & Beta & SE & & Beta & SE & & Beta & SE & \\
\hline (Intercept) & -35.671 & 1.814 & * & -23.394 & 6.148 & $*$ & -7.364 & 2.208 & $*$ \\
\hline water & -0.047 & 0.006 & * & -0.037 & 0.013 & $*$ & -0.064 & 0.015 & $*$ \\
\hline$(\text { water })^{2} \dagger$ & 0.028 & 0.018 & & -0.035 & 0.044 & & 0.088 & 0.033 & $*$ \\
\hline tree & 3.069 & 0.618 & * & 6.336 & 1.424 & $*$ & -2.680 & 1.483 & \\
\hline$(\text { tree })^{2}$ & -7.438 & 2.273 & * & -11.055 & 5.124 & $*$ & 4.496 & 1.723 & $*$ \\
\hline slope & 0.653 & 0.014 & * & 0.923 & 0.071 & $*$ & 0.325 & 0.050 & $*$ \\
\hline $\begin{array}{l}\text { human } \\
\text { (human) }{ }^{2} \dagger\end{array}$ & -0.779 & 0.017 & $*$ & -1.078 & 0.086 & $*$ & -0.415 & 0.062 & $*$ \\
\hline EM0195 & -9.533 & 4.047 & * & -18.614 & 8.839 & $*$ & -9.699 & 0.789 & $*$ \\
\hline (Intercept) & 0.296 & 0.021 & * & 0.614 & 0.065 & $*$ & 0.263 & 0.021 & $*$ \\
\hline water & -0.527 & 0.034 & * & -1.017 & 0.112 & $*$ & -0.477 & 0.035 & $*$ \\
\hline$(\text { water })^{2} \dagger$ & 2.126 & 0.575 & * & 4.743 & 2.482 & & 2.233 & 0.415 & $*$ \\
\hline tree & -8.508 & 2.317 & $*$ & -32.048 & 10.297 & $*$ & -7.829 & 1.465 & $*$ \\
\hline $\begin{array}{l}(\text { tree })^{2} \\
\text { slope }\end{array}$ & 0.719 & 0.037 & * & 0.815 & 0.013 & $*$ & 0.700 & 0.037 & $*$ \\
\hline EM0198 & -46.281 & 6.971 & * & -86.426 & 11.190 & $*$ & -38.357 & 8.130 & $*$ \\
\hline (Intercept) & 0.237 & 0.020 & * & 0.675 & 0.048 & $*$ & 0.145 & 0.021 & $*$ \\
\hline water & -1.112 & 0.115 & * & -4.443 & 0.329 & $*$ & -0.438 & 0.122 & $*$ \\
\hline$(\text { water })^{2} \dagger$ & 6.262 & 1.344 & * & 10.485 & 2.221 & $*$ & 5.500 & 1.381 & $*$ \\
\hline tree & -11.778 & 3.076 & * & -16.952 & 5.627 & $*$ & -10.837 & 3.151 & $*$ \\
\hline$(\text { tree })^{2}$ & 0.874 & 0.042 & $*$ & 1.234 & 0.066 & $*$ & 0.760 & 0.027 & $*$ \\
\hline slope & 1.542 & 0.191 & * & 2.968 & 0.347 & $*$ & 1.244 & 0.198 & $*$ \\
\hline
\end{tabular}

$\dagger$ Coefficients and standard errors were multiplied by 100 . 